\title{
ESSAY
}

\section{The James Leininger Case Re-examined}

\author{
Michael Sudduth
}

Submitted November 12, 2021; Accepted November 25, 2021; Published December 30, 2021

https://doi.org/10.31275/20212359

Creative Commons License CC-BY-NC

Beginning at age two in the spring of 2000, James Leininger began exhibiting behaviors and making claims that were later believed to resemble the life and death of World War II fighter pilot James Huston, Jr. Over several years, James Leininger provided information about World War II, especially fighter planes, as well as specific details that seemed to match facts about the life of Huston. In 2009 Bruce and Andrea Leininger published Soul Survivor, a book in which they narrated the chronology of events that eventually convinced them that their son was the reincarnation of Huston. In 2021 Bruce Leininger published a prize-winning essay focused solely on documenting the alleged evidence in support of this belief. ${ }^{1}$

On the face of it, the James Leininger case exhibits many of the strengths of an ideal case of the reincarnation type. First, the case involves a young child in Western culture who made veridical claims that seem to match important facts about the life and death of a formerly living person. Second, some of the important claims attributed to the child were apparently documented before anyone had identified the previous personality. Third, the child also exhibited behavioral patterns resembling the previous personality. Finally, prominent reincarnation researcher Jim Tucker investigated the case and concluded that it's a "spectacular example of the phenomenon of young children who seem to remember previous lives." Not surprisingly, many survivalists have regarded this case as one of the best-documented cases of the reincarnation type.

By contrast, skeptics have argued that no reincarnation hypothesis 
is needed to explain the experiences that form the foundation of the James Leininger narrative, nor is any reincarnation hypothesis needed to explain the behaviors and knowledge James subsequently exhibited over the course of several years and which constitute the scaffolding of the story (e.g., Fischer \& Yellin, 2016; Shermer, 2018). Rather, quite ordinary experiences, unsurprising coincidences, and common psychological tendencies adequately account for the basic facts of the story. For example, skeptics have argued that James could have easily seen or heard things about aviation and World War II which his parents didn't notice, but which influenced his behavior and knowledge. And promptings by adults who suggested a past-life interpretation of his experiences could easily have contributed to the reincarnation narrative, which was reinforced by a combination of malobservation, confabulation, and a variety of dubious inferences on the part of James's parents.

Researchers who think the Leininger case provides evidence for reincarnation regard the skeptical rejoinders as ill-informed, purely conjectural, and unable to account for the quantity and specificity of the veridical claims James made or the salient behavior he exhibited. Of course, Skeptics regard favorable assessments of the case as resting on unwarranted levels of credulity concerning what the facts are and shortsightedness concerning how otherwise sincere and well-meaning people can be self-deceived and blind to ordinary explanations of seemingly unusual or improbable events.

Over the past two years, I've investigated various aspects of this case. My inquiries have included a broad range of interviews, considerable historical research, and a careful examination of the Leiningers' telling and retelling of their story over the years. ${ }^{3}$ This has allowed an important but previously neglected fact-checking of the presumed facts of the case. Equally important, I've uncovered many previously unacknowledged facts that bear on the plausibility of ordinary sources of information shaping James Leininger's experience, behavior, and claims. In this paper I present my findings and discuss their implications for the assessment of the case as alleged evidence for reincarnation.

Jim Tucker was the first researcher to conduct a detailed investigation of the James Leininger case in order to assess its 
evidential value. His work has been the most thorough to date and the most cited in the literature. For these reasons, I will discuss the James Leininger case in the context of Tucker's earlier investigation and favorable analysis. I will also focus on James's behaviors and claims that were allegedly documented before anyone had identified the previous personality of James Huston, Jr. These "early-bird" items are ostensibly the case's strongest features, so much so that Tucker wrote an entire paper focused on these features of the case.

I will argue two main points. First, the early-bird items in the James Leininger case are not evidence for reincarnation. Second, a skeptical attitude toward this case as a whole is all things considered more reasonable than endorsing it as even modest evidence for reincarnation. I'm not arguing that the reincarnation hypothesis is false. I'm not arguing that there is no evidence for reincarnation. And I'm not arguing that there are no good cases of ostensible reincarnation. I'm arguing that the James Leininger case cannot reasonably be regarded as such a case.

Two kinds of general concerns support my skeptical assessment.

First, neitherthe Leiningers nor Jim Tucker has presented a narrative with a sufficiently robust chronology of events. Such a chronology must include contextual details that bear on the adjudication of various proposed explanations of the subject's behaviors and claims. The Leiningers and Tucker have failed to do this. As a result, their narratives exclude significant facts that increase the plausibility of ordinary sources of information shaping James Leininger's experience, behavior, and claims. These include the content of a Blue Angels aviation video James repeatedly watched and his exposure to World War II items on display at the Cavanaugh Flight Museum where he spent considerable time on at least two occasions. For reasons I'll explore, these facts significantly increase the plausibility of non-reincarnation explanations. Consequently, their exclusion creates a problem analogous to dark data in statistical reasoning-what you don't know matters. In the present case, the missing data create a deceptive appearance of plausibility for the reincarnation interpretation of the case.

Second, the plausibility of the reincarnation interpretation of this case depends essentially on there being a credible chronology of events. This in turn depends on the reliability of the Leiningers informing us what James said and when he said it, as well as their ability to give 
us a reasonable assurance that James was not exposed to sources of information that would plausibly have influenced his claims and behavior. I argue that the Leiningers do not satisfy a minimal threshold of reliability in these crucial respects since significant inconsistencies and factual errors vitiate their narrative, especially with respect to crucial features of the case. Moreover, their testimony over the years exhibits a variety of fact fudging and redactions of what James allegedly said and when he said it, typically after the Leiningers discovered facts about Huston's death that were inconsistent with James's claims as originally interpreted or reported.

In Section I I present a brief outline of Tucker's investigation and description of the case, together with his assessment of it, specifically with reference to early-bird items. Sections 2 and 3 address the first skeptical concern as a problem in Tucker's investigation and analysis. Sections 4 and 5 address the Leiningers' credibility problems. In Sections 6 and 7 I show the several ways the conclusions reached in previous sections undermine Tucker's favorable analysis of this case.

\section{TUCKER'S ACCOUNT OF THE JAMES LEININGER CASE}

Tucker first learned of James Leininger in 2002 as part of a planned $A B C$ television program Strange Mysteries featuring the James Leininger story and for which Tucker was interviewed but which never aired. After a series of phone conversations and email exchanges with the Leiningers in 2004, Tucker eventually interviewed them over two days in 2010, after the publication of their book Soul Survivor (hereafter, SS).

He published a lengthy discussion of the case in his book Return to Life (2013), and in 2016 he published a case report article which focused on James's early-bird testimony and behavior. ${ }^{4}$ Although the 2002 program never aired, the interviews for that program provided some documentation of James's behavior and claims his parents attributed to him before James's father Bruce allegedly identified James Huston, Jr. as the previous personality. Understandably, Tucker thinks the earlybird evidence is particularly important, so I'll focus on Tucker's 2016 paper below, supplementing it at points with his discussion in the Return to Life chapter. 
As Tucker explains, the events began in February 2000 when James was 22 months old. James's father took him to the Cavanaugh Flight Museum in Addison, Texas. James was particularly "fascinated by the planes and in particular by the World War II exhibit" (2016, p. 201). He spent nearly three hours at the museum and left with some toy airplanes and an aviation flight demonstration video of the Blue Angels purchased from the museum gift shop and which James watched "repeatedly for weeks" (2016, p. 201). Bruce took James to the museum again on Memorial Day weekend.

Within two months of his first museum visit, James began repeating the phrase "airplane crash on fire" and slamming his toy airplanes into furniture. He also began having nightmares and would shout out "Airplane crash on fire! Little man can't get out!" And he would thrash about and kick his legs in the air.

Tucker says James provided further details about his nightmares in the months that followed. And here Tucker provides an account of increasingly more specific claims. I quote at length for narrative context.

[James] indicated that [his dreams] were memories of events from the past. He said his plane had crashed on fire and that it had been shot by the Japanese. Two weeks after those statements, James said his plane was a Corsair ... and he talked about flying a Corsair several times...

On August 27, 2000, when James was 28 months old, he told his parents he had flown his plane off a boat. When his parents asked him the name of the boat, he said, "Natoma." After that conversation, his father searched online for the word and eventually discovered a description of the USS Natoma Bay, an escort carrier stationed in the Pacific during World War II. He printed out the information he found, and the footer of the printout includes the date he did...

James's parents asked him a number of times for the name of the little man in his dreams. He always responded with only "me" or "James." A few weeks after James gave the word Natoma, his parents asked him if he could remember anyone else who was with the little man. James responded with the name Jack Larsen.

One day when James was just over two and a half, his father was 
looking through a book he was planning to give his own father for Christmas, one called The Battle for Iwo Jima 1945. His father reports that James pointed to a picture showing an aerial view of the base of the island, where Mt. Suribachi, a dormant volcano, sits, and said, "That's where my plane was shot down."...

With the ongoing nightmares, James parents eventually contacted Carol Bowman, who had written a book about children's past-life memories. They began a lengthy correspondence. Following Bowman's advice, James's mother started acknowledging to him that the events he was describing had indeed happened to him before, while emphasizing that they were in the past and he was now safe. The nightmares then grew less violent and less frequent. (Tucker, 2016, p. 201)

Tucker provides further behavioral details-for example, when James began to draw, he drew planes in battle scenes with airplanes dropping bombs, and he wrote James 3 on the drawings, which he continued to do even after turning four years old.

As Tucker explains, when James began giving his parents more detailed information about his experiences and apparent recollections, his father Bruce began researching James's claims to see if they corresponded to anything factual. Bruce discovered that there was a Natoma Bay naval carrier that was stationed in the Pacific and took part in the Iwo Jima operations (allegedly verified on August 27, 2000). He later discovered that a man named Jack Larsen served on the carrier during the Iwo Jima operations.

Several months after the filming of the 2002 ABC program, Bruce Leininger attended a Natoma Bay reunion and acquired information that allowed him to verify several other facts. He learned that the Jack Larsen from Natoma Bay had survived the war. Though he was not at the reunion, he was still alive and James's father soon visited him. He also learned that only one pilot from the ship was lost during the Battle of Iwo Jima, a 21-year-old from Pennsylvania named James M. Huston, Jr. (Tucker, 2016, p. 201). Tucker (2016, pp. 201-202) further explains how, after the Natoma Bay reunion, Bruce Leininger discovered further details concerning Huston's death. Huston did not die on Iwo Jima itself, but at nearby Chichi Jima, but he was the only Natoma Bay pilot who died during the 
Battle of Iwo Jima. And Jack Larsen flew with Huston on the fatal Chichi Jima mission. Tucker says, "As Huston was the only pilot from Natoma Bay killed during the Iwo Jima operation, and as his details closely matched James's statements, his parents concluded that he was the man whose life James had recalled" (2016, p. 203). In the months that followed, James made further claims about Huston and WW/2 which the Leiningers confirmed.

Tucker's 2016 case report focuses on statements and behavioral patterns attributed to James in the 2002 unaired $A B C$ program, filmed before the previous personality of James Huston had allegedly been identified. Tucker provides a chart that compares the accuracy of these statements and behaviors with Huston. The chart (Table 1 ) is a reproduction of the one Tucker provided in his case report. Tucker's table shows the item/source documented in the 2002 program. The verifications and comments are mostly from sources consulted after the filming of the 2002 program.

Tucker tersely considers four possible explanations of the facts of the case: Fantasy, knowledge acquired through normal means, psimediated transfer, and reincarnation. After dismissing the first three, he concludes:

The documentation in James's case provides evidence that he had a connection with a life from the past. On the face of it, the most obvious explanation for this connection is that he experienced a life as James Huston, Jr. before having his current one. The facts in this case indicate that this explanation warrants serious consideration. (Tucker, 2016, p. 206)

In Return to Life, Tucker provides an expanded case discussion. For present purposes, the most important part concerns three other items Tucker says were documented before the Leiningers had identified Huston as the previous personality. The first is James signing his name James 3 on drawings he made between the ages of three and four. The second is James giving his parents the name Jack Larsen. The third is James giving the name Natoma as the name of the boat he flew his plane off of. Tucker mentions all three items in his 2016 report, but he does not put them in the category of early-bird claims there since 
TABLE 1

Statements and Behaviors by James Leininger Reported in ABC News Interview, as Compared with James Huston's Death ${ }^{\mathrm{a}}$

\begin{tabular}{|c|c|c|c|}
\hline Item & $\begin{array}{l}\text { Source of } \\
\text { Information }\end{array}$ & $\begin{array}{l}\text { Verification of Match } \\
\text { with Huston }\end{array}$ & Comments \\
\hline $\begin{array}{l}\text { "Mama, before I was } \\
\text { born, I was a pilot, } \\
\text { and my airplane got } \\
\text { shot in the engine, } \\
\text { and it crashed in } \\
\text { the water, and that's } \\
\text { how I died." }\end{array}$ & $\begin{array}{l}\text { James's } \\
\text { mother }\end{array}$ & $\begin{array}{l}\text { Memoir of veteran who saw } \\
\text { Huston's plane get hit. James's } \\
\text { father also talked to three eye } \\
\text { witnesses. One later told a } \\
\text { television interviewer, "I saw the } \\
\text { hit. I would say he was hit head } \\
\text { on, yeah, right on the middle of } \\
\text { the engine." }\end{array}$ & \\
\hline $\begin{array}{l}\text { Died in the Battle of } \\
\text { Iwo Jima }\end{array}$ & $\begin{array}{l}\text { Narration } \\
\text { states that } \\
\text { James may } \\
\text { have been } \\
\text { one of the } \\
\text { pilots who } \\
\text { died in the } \\
\text { Battle of } \\
\text { Iwo Jima }\end{array}$ & $\begin{array}{l}\text { History of Composite Squadron } \\
\text { Eighty One (VC-81) and aircraft } \\
\text { action report }\end{array}$ & $\begin{array}{l}\text { Huston was the one pilot } \\
\text { from USS Natoma Bay } \\
\text { killed during the Iwo Jima } \\
\text { operation. His plane was } \\
\text { shot down as he took part } \\
\text { in a strike against transport } \\
\text { vessels in a harbor on nearby } \\
\text { Chichi-Jima }\end{array}$ \\
\hline $\begin{array}{l}\text { Nightmares of plane } \\
\text { crashing on fire and } \\
\text { sinking and being } \\
\text { unable to get out }\end{array}$ & $\begin{array}{l}\text { James's } \\
\text { father }\end{array}$ & $\begin{array}{l}\text { Aircraft action report states no } \\
\text { wreckage of the plane was left } \\
\text { afloat }\end{array}$ & \\
\hline Flew a Corsair & $\begin{array}{l}\text { James's } \\
\text { mother }\end{array}$ & $\begin{array}{l}\text { Pictures of Huston with } \\
\text { Corsairs and squadron VF-301; } \\
\text { interviews by James's father } \\
\text { with veteran and son of veteran } \\
\text { who served with Huston in the } \\
\text { squadron }\end{array}$ & $\begin{array}{l}\text { James seemed to say that he } \\
\text { was flying a Corsair when he } \\
\text { crashed. This was incorrect } \\
\text { for Huston, who was flying } \\
\text { an FM-2 when he died, but } \\
\text { Huston had flown Corsairs } \\
\text { earlier when he made test } \\
\text { flights with VF-301 }\end{array}$ \\
\hline Plane flew off a boat & $\begin{array}{l}\text { James's } \\
\text { mother }\end{array}$ & $\begin{array}{l}\text { Numerous military records } \\
\text { document that James Huston } \\
\text { was a pilot on USS Natoma Bay }\end{array}$ & \\
\hline $\begin{array}{l}\text { His plane was } \\
\text { shot down by the } \\
\text { Japanese }\end{array}$ & $\begin{array}{l}\text { James's } \\
\text { mother }\end{array}$ & $\begin{array}{l}\text { History of Composite Squadron } \\
\text { Eighty-One (VC-81) and aircraft } \\
\text { action report }\end{array}$ & \\
\hline $\begin{array}{l}\text { Corsairs got flat tires } \\
\text { when they landed }\end{array}$ & James & $\begin{array}{l}\text { Air Force historian interviewed } \\
\text { in the segment stated Corsairs } \\
\text { bounced when they landed, } \\
\text { leading to flat tires }\end{array}$ & \\
\hline
\end{tabular}

a Interview conducted when James was four years old, before Huston was identified. 
he's classifying the early-bird claims solely based on whether they were mentioned in the $2002 A B C$ program, and none of these items were mentioned in the program.

Tucker includes these items in his expanded list of early-bird claims because there is alleged documentation for each. He saw the drawings James made when he was three (and later four) and signed James 3. An image of one of these is included in his 2016 case report. Based on a printout of Bruce Leininger's Internet search activity on October 16, 2000-he searched the name Jack Larsen-Tucker places James's giving the name Larsen around that date. Tucker's justification for including "Natoma" as an early-bird claim is a date/time-stamped computer printout of the entry on the Natoma Bay from the online version of the Dictionary of American Naval Fighting Ships. Bruce claims he printed this document the night James gave the name Natoma. Tucker includes an image of the document in his 2016 report.

\section{Evidential Force of the Case}

Tucker doesn't explain why the presumed facts he presents are evidence for reincarnation, much less how strong the evidence is supposed to be. He seems to link explanatory value and evidential value, as if the former converts to the latter. Even if that is plausible, it needs to be argued, especially since there is nothing obvious about the explanatory value of a hypothesis with poorly defined parameters and which is contrasted with a truncated set of competing explanations. To the extent that Tucker offers support for his evidential and explanatory claims, his reasoning is mostly impressionistic. Such reasoning exploits the psychological tendency of people to make certain kinds of inferences; it does not show that the inferences are cogent. Such reasoning also conceals, rather than critically engages, a variety of contentious assumptions. These are fairly widespread conceptual problems in the literature on survival which I've discussed at length elsewhere (Sudduth, 2016).

For present purposes, l'll set aside the above conceptual problems and assume that reincarnation can explain the facts in the James Leininger case. I will also assume that the facts Tucker has outlined are, all other things being equal, evidence for reincarnation-that is, the presumed facts in this case provide prima facie evidential support 
for the reincarnation hypothesis. The crucial question is whether all other things are equal, or whether there are considerations that defeat whatever evidential force we might initially be inclined to give the facts in this case.

In general, the evidential force of facts depends on two conditions:

(N) There are no additional facts that neutralize the evidential force of the presumed facts.

and

(D) There are no significant grounds for doubting the presumed facts.

If either $(N)$ or $(D)$ does not obtain, then the prima facie evidential force of facts in support of a particular belief, claim, or hypothesis is overridden or defeated. To be clear, if only one of the two conditions is not satisfied, then what is otherwise evidence for a claim cannot reasonably be taken as evidence for that claim. Below l'll argue that neither $(N)$ nor $(D)$ is true in the James Leininger case, specifically with respect to the case's presumed early-bird items. Therefore, we should not regard these features of the case as evidence for reincarnation. Moreover, given the nature of the problems which infect the early-bird items, as well as how these items relate to the rest of the case, we should also be skeptical of the case as a whole.

\section{A PRELIMINARY INVESTIGATIVE CONCERN}

Before delving into my findings, there is a preliminary investigative concern which should be addressed, especially since it bears on some of what l'll subsequently discuss. The time gap between the original events and Tucker's subsequent investigation of the events is problematic.

Although Tucker had "sporadic correspondence with James's parents for several years" prior to his in-person interview with them, he wasn't able to conduct an in-person interview until 2010. This was after the Leiningers had published their book and ten years after the initial events and about eight years after the Leiningers claimed to have located the previous personality(Tucker, 2016, p. 203). This is a considerable time 
gap. The wider the time gap, the greater the challenge to meticulously reconstruct a robust and credible chronology - that is, a factually rich chronology based on reliable testimony and documentation. This is the only way to provide reasonable assurance that conditions (N) and (D) above have been met.

Tucker is aware of the potential problems here. For example, he acknowled ges that a delay can create obstacles to getting the appropriate verification of alleged facts (Tucker, 2013, p. 79). He also concedes, "I might have been able to corroborate parts of [the Leininger case] more if I could have studied it sooner" (Tucker, 2013, p. 87). Of course, Tucker is convinced that the Leiningers' story holds up "very, very well," despite the liability he acknowledges.

I don't share Tucker's optimism. The specific issues I'll be addressing later in the paper will show why I don't think Tucker's optimism is warranted. But we can note here a few reasons why we should be suspicious of Tucker's optimism even before considering my findings.

First, contemporaneous notes or other forms of detailed documentation help with accurately reconstructing past events, but the Leiningers lost or discarded the notebook in which they kept notes of the unusual events they were watching unfold over several years (Tucker, 2016, p. 203). Tucker says this happened shortly after the Leiningers published their book, but he doesn't regard it as "fatal" to the case since "verification is available for much of the story" (Tucker, 2013, p. 79). These include the content of the unaired 2002 ABC program, primary source documents concerning the circumstances of Huston's death, and documents the Leiningers have presented but which are not independent of their testimonial claims about the genesis and context of the documents. For reasons to be explored later, these are meager verifications at best.

Second, Tucker admits that James's behavior from ages two to five play an important role in this case-for example, James's waking up from nightmares in a panic, his practice of crashing toy airplanes into his parents' coffee table, his mimicking aviator behavior, and his later drawings of warbirds in combat. Tucker thinks this behavior is consistent with post-traumatic play. Since there is allegedly no trauma in James's past in his present life, Tucker leverages this to support the conjecture that the trauma must have been in a past life. 
But Tucker never directly observed James's relevant behavior. He had to rely on videos and what James's parents and relatives had to say about what they observed. While some of the reported facts may be accurate-for example, James crashed planes into furniture and broke off the propellors of his planes-what's crucial is the interpretation of the behavior. But the witnesses were not trained in child psychology or psychiatry and so can't be trusted with a nuanced interpretation of what they observed. It's reasonable to ask how well-justified a post-traumatic play conjecture can be in the absence of first-hand observations of and/or interviews with the subject close to the time he displayed the behavior in question. ${ }^{5}$

Finally, the chronology of events covers several years, roughly from February 2000 to September 2006, at which time James's parents took him to Futami Harbor, the crash site of James Huston. While the foundational events and claims of the case occurred between spring 2000 and early fall 2000 , much of the scaffolding of the case comes from a broad range of incidents from fall 2000 to the summer 2002, prior to the Leiningers identifying Huston as the presumed previous personality. And from fall 2002 to spring 2004, there's another list of claims attributed to James concurrent with Bruce Leininger's further historical research into details about the Natoma Bay and the death of Huston.

The lengthy timeline invites many ordinary sources to shape James's experience, behavior, and claims. As I'll show below, there's a proliferation and aggregation of occasions of exposure-that is, experiences James had involving salient information. If these exposures are not highly plausible sources of James's claims and behavior, they at least muddy the water, for they would make it exceedingly difficult to distinguish between sources which supplied information and sources which confirmed what James knew independently of such sources.

Tucker's lecture and interview presentations of the case tend to obscure this crucial point. He tends to provide an itemized list of James's claims and their alleged verifications abstracted from the complex and protracted chronology to which they are tied. And even when he provides the sequence of events, considerable ambiguity vitiates the presentation. Presumably Tucker wishes to present the cumulative weight of all the facts and not take them in isolation from each other. A noble goal. But it's equally important to have a clear chronology that 
acknowledges and includes salient contextual details_-for example, the ordinary sources available to James at various stages in the narrative. Without such a robust chronology, Tucker runs the risk of analyzing a narrative which is predisposed to favor an extraordinary explanation of what are in fact ordinary phenomena. Without a robust chronology of events, we're flirting with confirmation bias.

Some of the concerns above could've been mitigated had Tucker interviewed the Leiningers in 2004 or earlier. Regardless of the reasons for the delay, it impeded a professional investigation of the veracity of the Leiningers' claims. Between 2004 and 2010, the "facts" had ample time to evolve, or what is just as probable, certain potentially inconvenient facts had ample time to be consigned to an epistemically inaccessible past. While the Leiningers appear interested in presenting evidence that their son is the reincarnation of James Huston, Jr., it's at least problematic that they didn't permit at least one qualified investigator to document and underwrite their claims in a timely manner.

\section{SIGNIFICANT FACTS EXCLUDED FROM TUCKER'S ANALYSIS}

Above I said that a necessary condition of the facts Tucker presents being evidence for the reincarnation hypothesis is:

(N) There are no additional facts that neutralize the evidential force of the presumed facts.

All inductive reasoning, including explanatory reasoning, is subject to a total evidence requirement. It's relatively easy for facts to offer evidential support for any hypothesis or theory. Every instance of the fallacy of stacking the deck-only considering the evidence that favors one's preferred theory-demonstrates this truism. And it's just as easy for any positive evidential status to diminish with the acquisition of new facts. For this reason, we have to consider as many salient facts as possible, especially facts that (greatly) lower the plausibility of a hypothesis. ${ }^{6}$

In this section, l'll consider a large number of such facts which significantly lower the evidential force of Tucker's early-bird items. These are facts Tucker has excluded from his analysis, and in some cases not 
even acknowledged. They are facts that reduce the plausibility of the reincarnation hypothesis Tucker proposes, and they do so by raising the plausibility of non-reincarnation explanations of the early-bird claims. The facts concern James's wider experience and exposure to ordinary sources of information that plausibly shaped his claims and behavior. Among these known exposures are videos James watched and at least two lengthy visits to the Cavanaugh Flight Museum in Addison, Texas.

The exposures discussed below are significant for two reasons. First, they have explanatory relevance. James was exposed to information which appears as the content of his claims and which illustrates the behavior he displayed. So, he was exposed to potential ordinary sources of information that influenced his claims and behavior. More specifically, his exposures satisfy lan Stevenson's criterion of explanatory relevance. In discussing the explanatory force of appeals to ordinary sources of information, Stevenson says, "It is one thing to speculate on possible sources of information and quite another to show a specific matching between a subject's statements and a definite source of information providing the ingredients of those statements" (Stevenson, 1974, p. 340). Second, the exposures were temporally prior to and concurrent with James's claims and behaviors. Not a few claims and behaviors, but nearly everything between spring 2000 to spring 2002. These are items the Leiningers and Tucker invest with considerable evidential significance, and which constitute the foundation of the James Leininger narrative.

\section{The Blue Angels Video}

Although not mentioned in the 2004 ABC Primetime television segment, when Bruce took James to the Cavanaugh Flight Museum in February 2000, he purchased at least one toy airplane and a Blue Angels video for James from the museum gift shop. James repeatedly watched the video for months (SS, pp. 21-22, 24, 57, 118). Although Tucker makes reference to this potentially significant contextual detail, he never watched the video. His explanation is straightforward: He couldn't locate it (Tucker, 2013, p. 67; 2016, p. 201). Yet, he doesn't consider this problematic. Referring to James's first visit to the Cavanaugh Flight Museum, Tucker writes: 
When they left after three hours, James had some toy planes, as well as a video called It's a Kind of Magic about the Blue Angels, the Navy's flight exhibition team. James loved the video, and he watched it repeatedly for weeks. The trip and the video started (or uncovered) his love for planes. This passion may have led to some of the knowledge of planes and flying that James often surprised his parents by voicing. The video, however, was clearly not the source of James's information about World War II, since the Blue Angels group was founded in 1946 after the war ended. (Tucker, 2016, p. 201)

If Tucker couldn't find the video, that's not surprising. Bruce Leininger gave the name of the video as It's a Kind of Magic (SS, p. 24; cf. Tucker, 2016, p. 201). But this is incorrect. There is no Blue Angels video by that name. The video (Figure 1) is actually called Blue Angels: Around the World at the Speed of Sound (1994, A\&E Home Video), narrated by Dennis Quaid and featuring the Queen song "It's a Kind of Magic." To confirm this, I relied on photos of the VHS tape James watched which Bruce Leininger sent to researcher Leslie Kean. ${ }^{7}$

One might suppose that being mistaken about the title of the Blue Angels video is an insignificant factual error, except that it apparently prevented at least one qualified researcher from locating it and examining its content. And if the content is salient, the error is greatly consequential.

Tucker concedes that the Blue Angels video might be the source of some of James's knowledge of planes and flying. Of course, had Tucker seen the video, he could offer more than a conjecture here. He'd be able to say which claims attributed to James could plausibly have been derived from the video, or how the video might have otherwise shaped James's experiences and the evolving narrative of his experience. Instead of illuminating the case in this way, he dismisses the importance of the video. He reasons that since the Blue Angels were formed in 1946, after WW2, the video clearly was not the source of James's knowledge about World War II.

As it happens, discussion of WW2, often with archival footage, was common in the Blue Angels videos produced in the 1990s. That's because there are several connections between $\mathrm{WW}_{2}$ and the formation of the Blue Angels, including the motivation for forming the Blue Angels, the technology that was used, and the pilots who flew the 


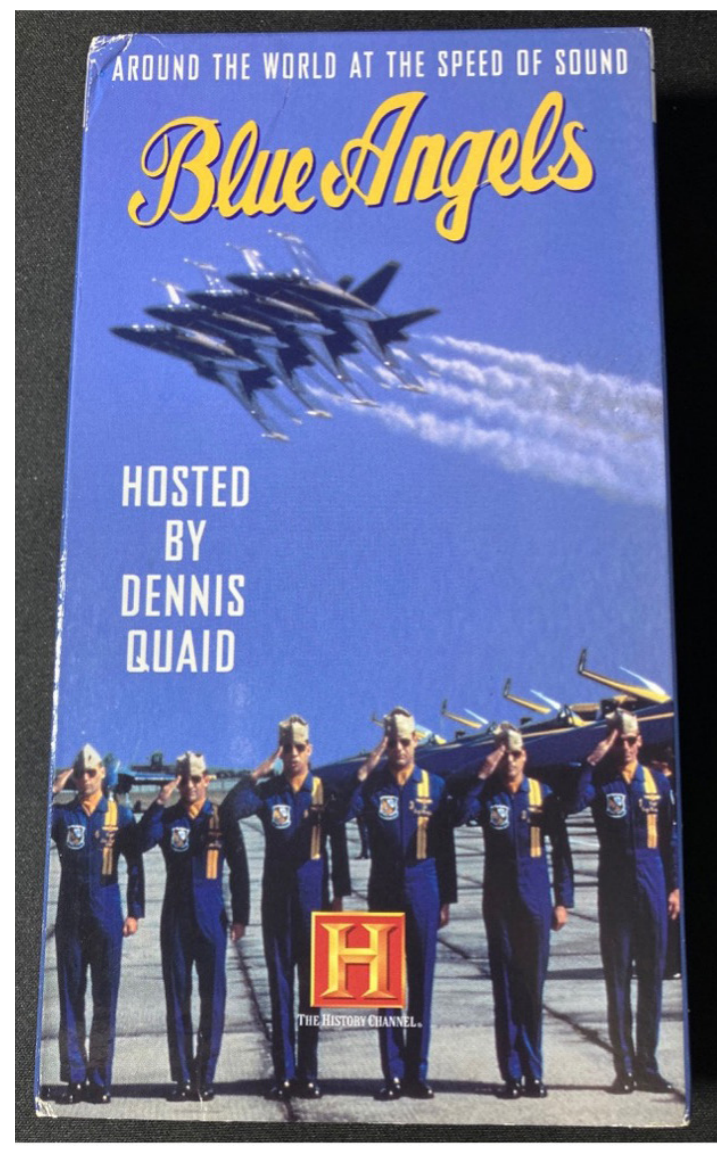

Figure 1. Cover to the 1994 Blue Angels VHS Tape. (Photo credit: Michael Sudduth)

planes. And the Blue Angels video James watched was no exception. It contains a 10-minute segment on WW2 with archival footage. ${ }^{8}$

More importantly, Tucker's reasoning is a red herring. Many of the evidentially salient features of this case aren't about James's knowledge of WW2 or his apparent knowledge of James Huston. Between May and August 2000, James made many claims about planes and about the content of his nightmares. These form the foundation of the case, but they are not explicitly about WW2 or James Huston. And this is true of the claims Tucker thinks make the case a strong one. Of the seven early-bird items that are the focus of Tucker's 2016 case report, at the 
most three are about WW2 and broadly related to Huston's role in the war, namely his death taking place during the Battle of Iwo Jima, being shot down by the Japanese, and his claiming to have flown a Corsair.

Moreover, as Tucker himself acknowledges, the case isn't merely about veridical claims concerning Huston's role in the war. It's also about behavior suggestive of Huston's experience as a fighter pilot and the circumstances and manner of his death. "This case," Tucker says, "involves a boy who displayed behaviors that suggested he was recalling a traumatic crash" (Tucker, 2016, p. 203; cf. 2016, p. 201). Item \#3 on Tucker's list (in Table I) concerns James's recurring nightmare experience of flying a plane that was shot, caught on fire, and crashed in the water. The behaviors also include James crashing planes into a family coffee table while saying "Airplane crash on fire," his recurring nightmares of a plane crash, and his panicked mimicking of the movements of someone seemingly trapped and trying to extricate himself from a compartment.

If Tucker never watched the video, he's poorly positioned to rule out the salience of the video as something that might have contributed to James's behavior. And since James's waking state behavior consists of his acting out or conveying what he was experiencing in his dreams, the question to ask is whether the content of the video might have contributed to James's nightmares. Without seeing the video, Tucker is in no position to rule it out as a plausible source of the experiential and behavioral features of the case. ${ }^{9}$

But the Blue Angels video is relevant for another reason. The Leiningers emphasize many of James's claims and behavior related to general aviation as evidence of his having lived a previous life. For example, by the time James was four years old, he had expressed a desire to fly an "F-18 Hornet" and be a "slot pilot" (SS, p. 127), was able to identify the tailhook as a distinctive feature of naval planes (SS, p. 130), could mimic settling into a cockpit, including adjusting the headgear (SS, p. 126-27), and bringing himself to attention and saluting (SS, p. 120). The Leiningers regard these items as atypical for a child his age and suggestive of an old soul inhabiting James's body, a soul intimately familiar with aviation.

So, what is the content of the Blue Angels video? And how does it plausibly illuminate aspects of this case? 
Contrary to what Tucker and the Leiningers would lead us to believe, even a cursory viewing of the Blue Angels video shows that its content is highly relevant to James's nightmares, his behavioral patterns, and the kinds of claims for which his parents-on whom Tucker heavily relies to convey salient facts-could find no normal explanation.

-All of the claims and behaviors the Leiningers attribute to James (above) as something ostensibly remarkable and for which they could identify no normal source are either mentioned or visually represented in the video, some nearly a dozen times-for example, the naval salute, carrier landings, fighter planes with tail hooks, and aviation terminology such as "slot pilot." (Atkeison, 2020, 0:06:25-0:06:30, 0:07:18-0:07:20, 0:08:18-0:08:20, 0:14:38-0:15:27, $0: 23: 28-29,0: 24: 50-0: 24: 54,0: 40: 34-0: 40: 38.)^{10}$

-There is a 10-minute segment on WW/2 that discusses the connection between WW/2 and the Blue Angels, including a specific reference to the war in the Pacific and the importance of naval carriers to that aspect of the war. This segment includes archival footage of fighter planes landing on carriers (e.g., AT-6 Texan) with tailhooks visible, images and archival footage of Grumman F6F Hellcats (a prominent fighter plane in the latter part of the war in the Pacific), and it emphasizes how some of the first Blue Angel pilots were war heroes of WW2 (Atkeison, 2020, 0:14:40-0:23:00).

- A pilot named Larsen appears in this video (name on screen), the pilot of the Blue Angels equipment transport plane, a Lockheed C-130 named after the children's television show Fat Albert (Atkeison, 2020, 0:52:42-0:54:00). Recall that James allegedly gave the name Larsen as the name of a pilot who appeared in his dreams.

-Proximate to footage of fighter planes taking off and landing on naval carriers, there is archival footage of an American fighter plane shooting down an Iraqi MiG, the back end of which explodes after being hit with a rocket. An aerial shot of fighter planes dropping bombs on land targets follows this (Atkeison, 2020, 0:51:360:51:46).

James's early behaviors, his use of aviation language, and his demonstration of knowledge of naval fighter planes_all of which impressed and bewildered his parents-clearly mirror information 
verbally and visually conveyed on the Blue Angels video.

What's crucial here is not that the Leiningers regard these items as evidentially strong-this obviously undermines their credibility, something l'll discuss below. But there's a downstream consequence on Tucker's own account and analysis of this case. In addition to his not acknowledging the content of this video and its bearing on the case, he assumes that the Leiningers are reliable judges of the ordinary sources of information James was exposed to (Tucker, 2013, p. 83). Yet they failed to inform Tucker of just how much of their child's Huston profile is found on a video he was regularly watching for months, so much that his father had to replace the video with new copies. Tucker's analysis of the case depends on the Leiningers having a degree of reliability in at least one crucial respect that they do not have.

What's most significant, though, is that some of the content of the video is clearly relevant to aspects of the case Tucker thinks are especially salient to the reincarnation interpretation.

- Contrary to what Tucker suggests, there is material on WW/2 on the video, including archival footage of $W_{W} / 2$ planes landing on carriers. That this material establishes a connection between WW/2 and the Blue Angels is not insignificant given James's early idolizing of the Blue Angels.

- Tucker was unaware that the video shows vivid imagery of a plane on fire after being shot during combat, nor was he aware that the video shows fighter planes dropping bombs on land targets. That this segment is proximate to the material on WW/2 is also significant as it ties together two crucial threads: WW/2 and a fighter plane on fire after being shot in combat.

I'll return below to the Leiningers' repeated assurances that James was not exposed to any images of planes on fire or being shot down. Clearly, he was. James repeatedly watched a video in which planes take off from and land on aircraft carriers. There are multiple references to WW2, the war in the Pacific, and the combat-ready nature of the Blue Angels, including archival footage of $W_{2} W_{2}$ fighter planes. The video also exposed James to vivid images of a fighter plane being shot in combat and exploding on fire in the air, followed by scenes of land targets being bombed. 
As l'll develop in the next subsection, the video wasn't James's only exposure to such vivid imagery, but even if were, it would still be a significant fact in the causal vector of the experiences that form the genesis of the narrative. It's unsurprising that a toddler who repeatedly watches a video with such images would develop nightmares in which he's flying a plane, gets shot, and his plane catches on fire and crashes in the water. ${ }^{11}$ Nor is it surprising that this fear would motivate James's repeated claims about his family members dying in planes taking off from the Lafayette Regional Airport (SS, pp. 37, 48-50, 76). What is surprising is that his parents were apparently unaware of the content of this video or were aware of it but didn't think it was significant. ${ }^{12}$

Now let's consider how the video bears on Tucker's list of earlybird claims.

Of the seven items Tucker lists in Table 1, the Blue Angels video is a plausible source for at least three of those items. The Blue Angels video contains several scenes of planes flying off a boat (item \#5 in Table 1). And items \#1 and \#3 convey the content of James's recurring dream. Surely, it's at least plausible that the video's graphic depiction of a fighter plane exploding in the sky after being shot during combat and bombs being dropped on land targets contributed to James's dreams. Perhaps other factors also played a role-for example, family stress from the recent move from Texas to Louisiana, James's hearing news reports about any of the several commercial plane crashes between February and May 2000, seeing his father off multiple times at the airport and indicating that his father's plane was going to crash, aviation amusement park rides proximate to the intensifying of his dreams, and his recently turning two, the age at which toddlers begin having nightmares. What would've been genuinely surprising is if James had no nightmares under these circumstances in this period of his toddler life.

From the beginning, skeptics proposed the possibility that James was exposed to something in his ordinary experience which triggered his nightmares or informed their content. But we don't need to posit a mere hypothetical possibility. We know the kinds of salient imagery he was exposed to while watching the Blue Angels video, and the exposure was long-term and repeated. We know his general life circumstances. We're not at a loss to offer plausible conjectures as to what ordinary 
events and experiences might've triggered James's nightmares.

But James also claimed that his plane was shot down by the Japanese, whom he identified by the symbol of the "big red sun," that he flew a Corsair, that Corsairs tended to get flat tires, and that he died in the Battle of Iwo Jima. What about these four early-bird claims?

This requires that we look at another important source of information in James's experience, partially concurrent with his exposure to the Blue Angels video, namely his trips to the Cavanaugh Flight Museum.

\section{The Cavanaugh Flight Museum}

According Bruce and Andrea Leininger, Bruce took James to the Cavanaugh Flight Museum in Addison, Texas, in February 2000 and again on Memorial Day weekend the same year. Despite the Leiningers mentioning this in their book, researchers discussing this case have routinely ignored or marginalized this aspect of the case. Tucker, for example, mostly ignores it. This is particularly astonishing since James's nightmares began no later than May 1, 2000, a couple of months after his first visit to the museum (SS, p. 3). And about two weeks after the second visit, around mid-June, James first began to verbalize the content of his nightmares (SS, pp. 28, 33-34).

The Leiningers say that Bruce and James spent nearly three hours at the museum on their first visit. During this time, James was mesmerized by the WW2 planes_-including the "F-104 Thunderchief ... Mustangs and Spitfires and Wildcats"(SS, pp. 23-24). We're also told that "James spent a lot of time browsing among the toy airplanes" in the museum's gift shop where the ticket office is located (SS, p. 24). We also know that James and Bruce were separated at least once because Bruce had moved on to a hangar which displayed more recent planes only to discover that James was not with him and had returned to the hangar with the WW2 planes (SS, p. 24). After Bruce purchased a toy airplane for James-we're not told the model of aircraft-and a Blue Angels video, he took James to watch planes take off at the Addison Airport (SS, p. 25).

There isn't much detail about the second visit at the end of May. It seemed to have been similar to the first visit, except that on this 
occasion Bruce and James had a conversation with Charles R. Bond, Jr., a war veteran who flew a P-40 Warhawk with the Flying Tigers in WW/2 (SS, p. 25). It's unclear how long this conversation lasted or the extent of its content. We're only told that Bond identified himself, indicated that he had flown a plane like one of the planes in the hangar, and gave James an Angel pin. Unlike the first trip, Bruce took pictures of James at the museum.

Shortly after the Leininger case received public attention in connection with the airing of the 2004 Primetime episode, skeptics claimed that James most likely saw things at the Cavanaugh Flight Museum which influenced him. Since the museum has WW2 planes and other WW2 memorabilia on display, the general skeptical concern is reasonable, especially since the Primetime episode neglected to mention James's visits to the museum. Some skeptics have offered more specific arguments. For example, Michael Shermer (2018, p. 105) has argued that James's ability to identify the Corsair plane by name stems from seeing a Corsair on display at the museum. Similarly, Fischer and Mitchell-Yellin (2016, p. 127) propose that James's experience of interacting with a Corsair plane during his museum visit may plausibly explain his subsequently dreaming he was flying one. In response, Tucker (2013, p. 69) has claimed that there was no Corsair plane on display at the museum when James visited in 2000, and so the museum could not be the source of James's knowing the name of the plane or his ability to identify it. ${ }^{13}$

Tucker is correct about there being no actual Corsair plane on display at the Cavanaugh museum when James visited, but this is a weak response to the skeptical objection. Seeing an actual Corsair plane is not the only way James could plausibly have learned the word Corsair and associated the word with the distinctive looking inverted gull wing WW2 plane. A toddler who spends three hours at a natural history museum doesn't need to see a life-sized reconstruction or reproduction of a Tyrannosaurus Rex to learn the name of this particular dinosaur and how to identify it. But also, Tucker's response doesn't as much as even address the general skeptical objection, which is that it's plausible that the lengthy museum visits influenced James in some salient manner-James's ability to identify the Corsair plane is only one of many items of knowledge he exhibited. 
But Tucker's response is otherwise problematic. The Corsair plane Tucker tells us was not at the Cavanaugh Flight Museum in 2000 when James visited was actually located in James's hometown of Lafayette, Louisiana, housed at the Lafayette Regional Airport, where James often journeyed to see his father off on business trips. It was also rolled out at various times for public events like the Sertoma Cajun Air Festival which James attended. Tucker attempts to eliminate the possibility that James saw a particular plane at a location 600 miles away from his home by proving that the plane wasn't at the location when James visited. This is not an effective dialectical strategy if that very plane was actually located 3 miles from James's front door at a location he frequented. I'll discuss this further below as it merits separate treatment, but clearly Tucker's rejoinder to the skeptical objection gets no mileage.

Let's not lose sight of the central investigative flaw here. Although Tucker contacted the Cavanaugh to discredit one particular skeptical objection, that's where his inquiry ended. He didn't inquire as to whether the museum had photos or artwork of Corsair planes on display, or model/toy Corsairs available in the gift shop. He didn't ask whether there were aviation videos on display for visitors to view, nor whether such videos had archival WW/2 footage. Tucker didn't do any Internet sleuthing to acquire information about the layout and contents of the museum in 2000, nor did he acquire a museum guidebook from the time period to help with this. As a result, the general skeptical objection remains intact.

Recall Ian Stevenson's well-advertised criticism of skeptical objections: "It is one thing to speculate on possible sources of information and quite another to show a specific matching between a subject's statements and a definite source of information providing the ingredients of those statements"(Stevenson, 1974, p. 340, emphasis mine). I did precisely the latter with the content of the Blue Angels video. We can do the same with the Cavanaugh Flight Museum. We can do more than speculate about what James could have learned there because of what could have been on exhibit there. If we know what was on display at the museum when James visited, as well as the length of James's visits and the parts of the museum where he spent considerable time, we can make plausible inferences about information he acquired during his two known visits there. 
As it happens, the contents of the museum when James visited are knowable. I consulted the 1999 Cavanaugh Flight Museum Guidebook and the Cavanaugh Flight Museum website for the years 1999, 2000, and 2001. ${ }^{14} \mathrm{I}$ also corresponded with Christy Bonds (assistant in the Cavanaugh Flight Museum gift shop 2000-2001 and 2003-2007, and manager of the gift shop 2007-2011) and Cassidy Rees (Gift Shop Associate at the Cavanaugh 2019-present). Bonds and Rees provided answers to about a dozen questions concerning the museum and its gift shop. Based on these sources, I compiled the following list of some of the relevant items that were on display when James visited the museum in February and May 2000.

—Large W/W2 Japanese battle flag with the Japanese "red dot" symbol.

-Artwork and photography of warbirds in the museum gallery, including large artwork depicting the Corsair in combat over islands.

-B-25 and Spitfire drop tanks. ${ }^{15}$

-P-51 Mustang. ${ }^{16}$

-FM-2 Wildcat with a drop tank, the type of plane Huston crashed in.

-A room called the Canteen where visitors could watch aviation videos focused on WW/2 and Vietnam.

—A variety of model and toy Corsair planes in the museum gift shop.

Let's consider the significance of these items, together with images of some of the salient items and exhibits. They correspond nicely to the six WW2 related claims attributed to James in the months following his museum visits in 2000.

i. The month following his first visit to the museum-March 14, specifically_James was able to identify a drop tank, the exterior fuel tank fighter planes often had to extend their mileage range. There was a bin full of toy airplanes and boats outside Hobby Lobby and James's mother had pointed to part of a plane and said it had a bomb on it. James said, "That's not a bomb, Mommy. That's a dwop tank" (SS, p. 17; cf. Tucker, 2013, p. 81). See Figures 2, 3, and 4 taken from the Cavanaugh webpage in 2000 . 


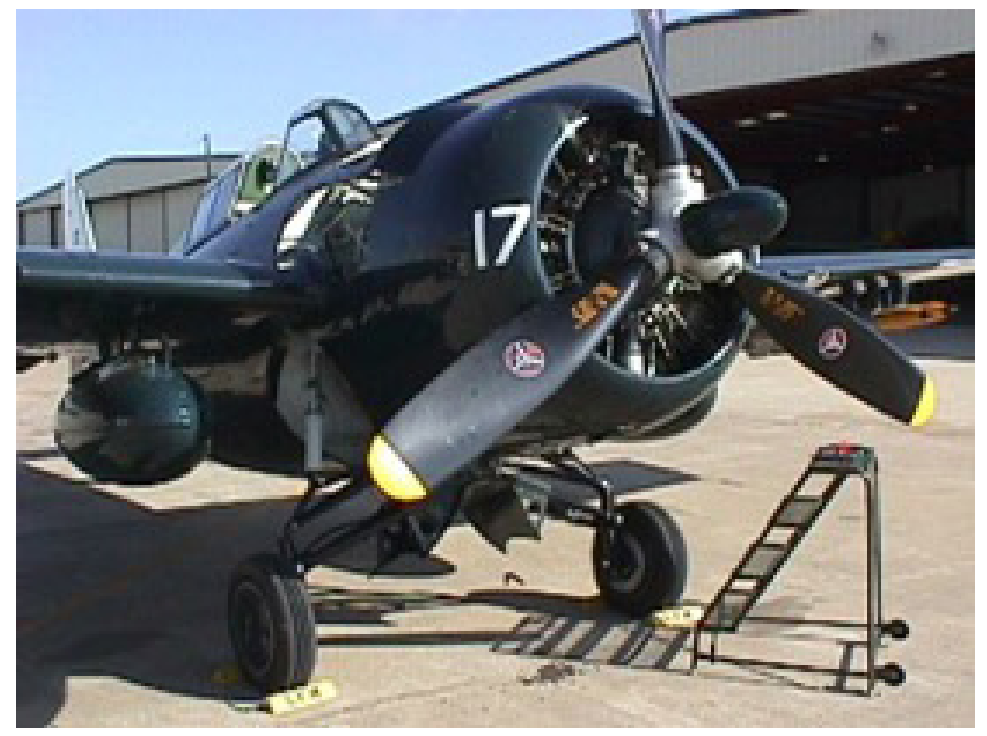

Figure 2. FM-2 Wildcat with Drop Tank (below wing). Photo credit: Cavanaugh Flight Museum

Figure 3. B-25 Drop Tank. Photo credit: Cavanaugh Flight Museum
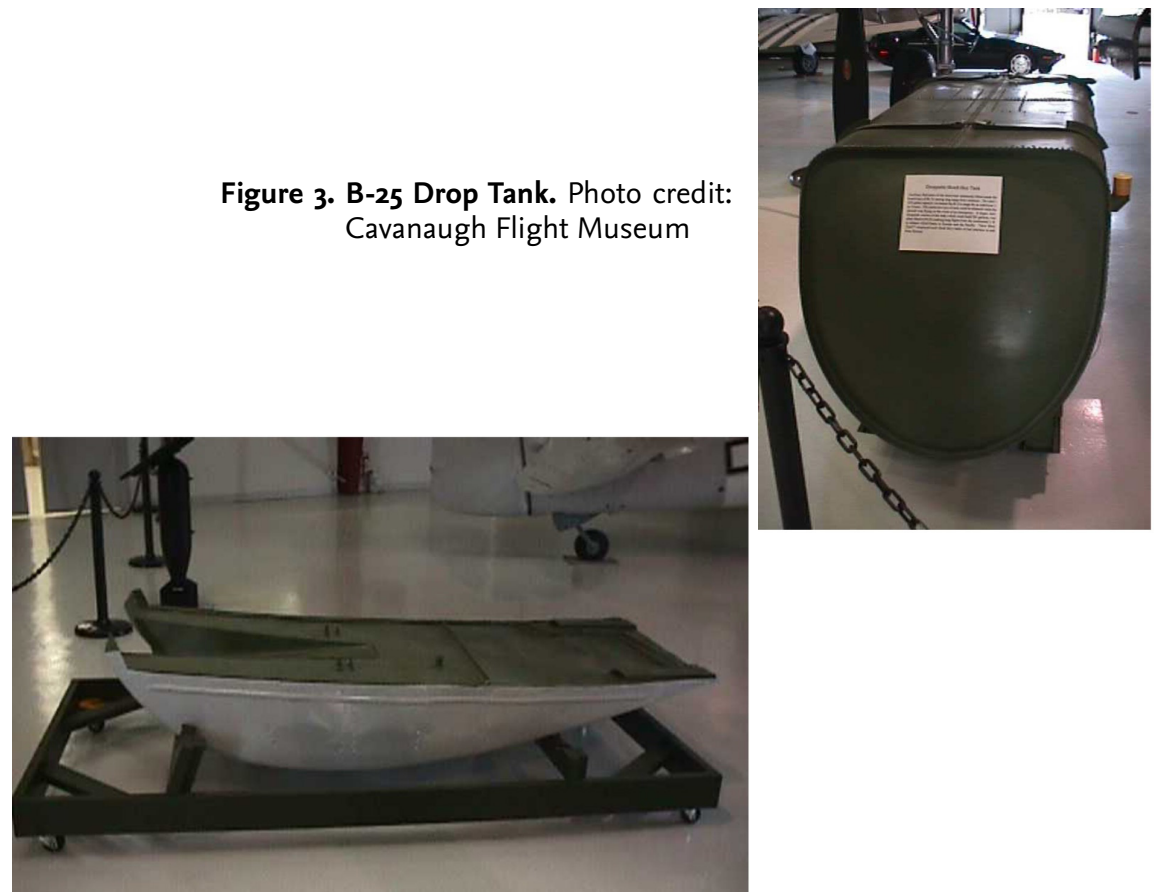

Figure 4. Spitfire Drop Tank. Photo credit: Cavanaugh Flight Museum 
ii. In May 2000, James's nightmares began, and by June he was able to describe some of the content of the dream. What did he describe? At first, he described his plane crashing and there being a big fire (SS, pp. 33-34). Then that he was trapped and unable to escape (SS, pp. 55, 63-64). Eventually he said his plane was shot down (SS, p. 65). See Figures 5 and the Blue Angels video. Figure 5 is a 2021 photograph of image that was in the museum gallery in 2000.

iii. In August 2000, he spoke of flying a Corsair off a boat (SS, p. 79). See Figures 5 and 12-These large framed paintings were in the gallery in 2000, though the photographs of the artwork were taken in 2021. Figure 5 is a 2021 photograph of an image that was in the gallery in 2000. Figures 6, 7, and 8 are 2021 photographs of the toy section and illustrate the kinds of toys and model planes, including Corsairs, which would have been on display and available for purchase in 2000.

iv. In August 2000 he spoke of being shot down by the Japanese (SS, p. 79). When asked how he knew it was the Japanese who shot him down, he told his parents it because of "the big red sun," a clear reference to the red dot symbol the Japanese used (SS, pp. 65, 69-70). See Figures 9 and 10, both of which are 2021 photographs of the same flag that was at the museum in 2000.

v. Andrea Leininger, in her early correspondence with Carol Bowman, said James was able to identify the P-51 Mustang (SS, p. 116). This plane was on display at the Cavanaugh museum, which even the Leiningers mention in passing (SS, p. 24). See Figure 11, which is from the Cavanaugh website in 2000.

vi. In November 2000, while Bruce Leininger was looking through a book on Iwo Jima (Wright, 1999, p. 3), James pointed to an aerial view of Mount Suribachi on the south end of Iwo Jima with its beach areas and said that's where his plane was shot down (SS, p. 104). See Figure 12. The image was at the museum in 2000 , though the photograph was taken in 2021.

As the Leiningers sum it up: "There were the tantalizing clues: the big red sun, the Japanese involvement, the fact that James thought he himself was the guy trapped in the burning plane" (SS, p. 72). These might be tantalizing if James had not been exposed to such imagery on multiple occasions beforehand. But this is simply not the case. 


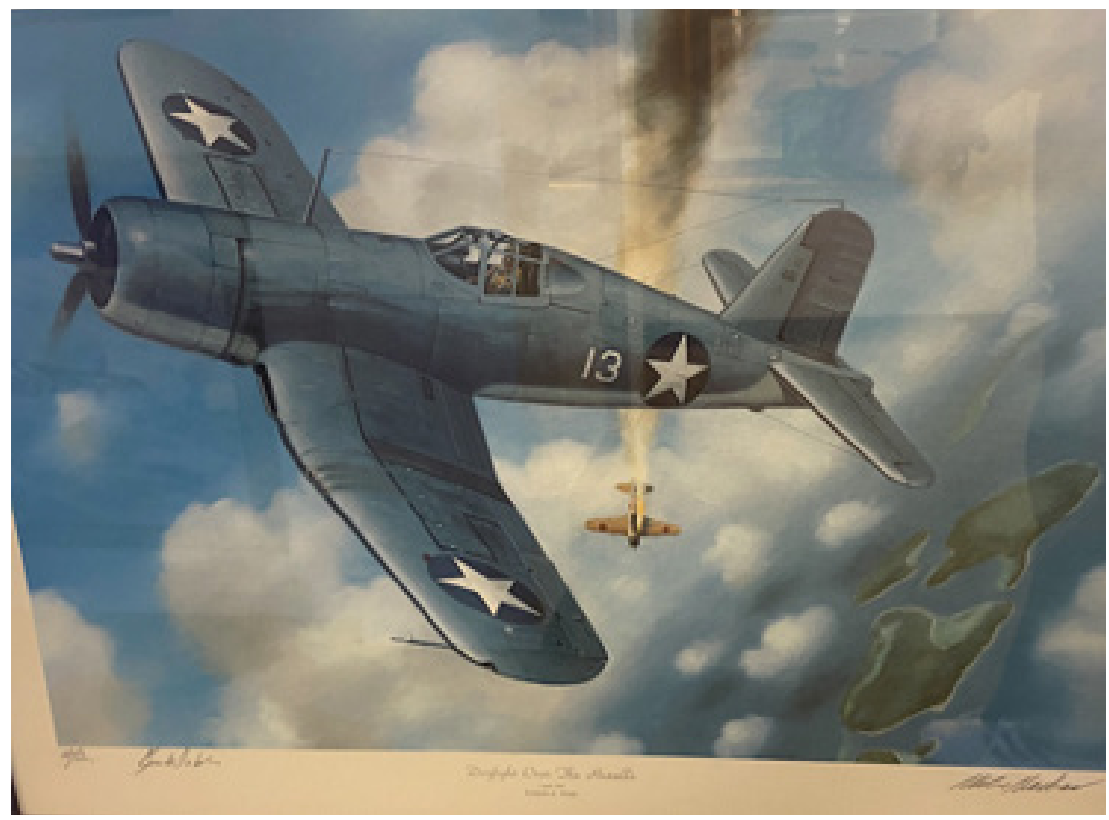

Figure 5. Corsair in "Dogfight Over the Russells" (by Walsh). Photo credit: Cavanaugh Flight Museum

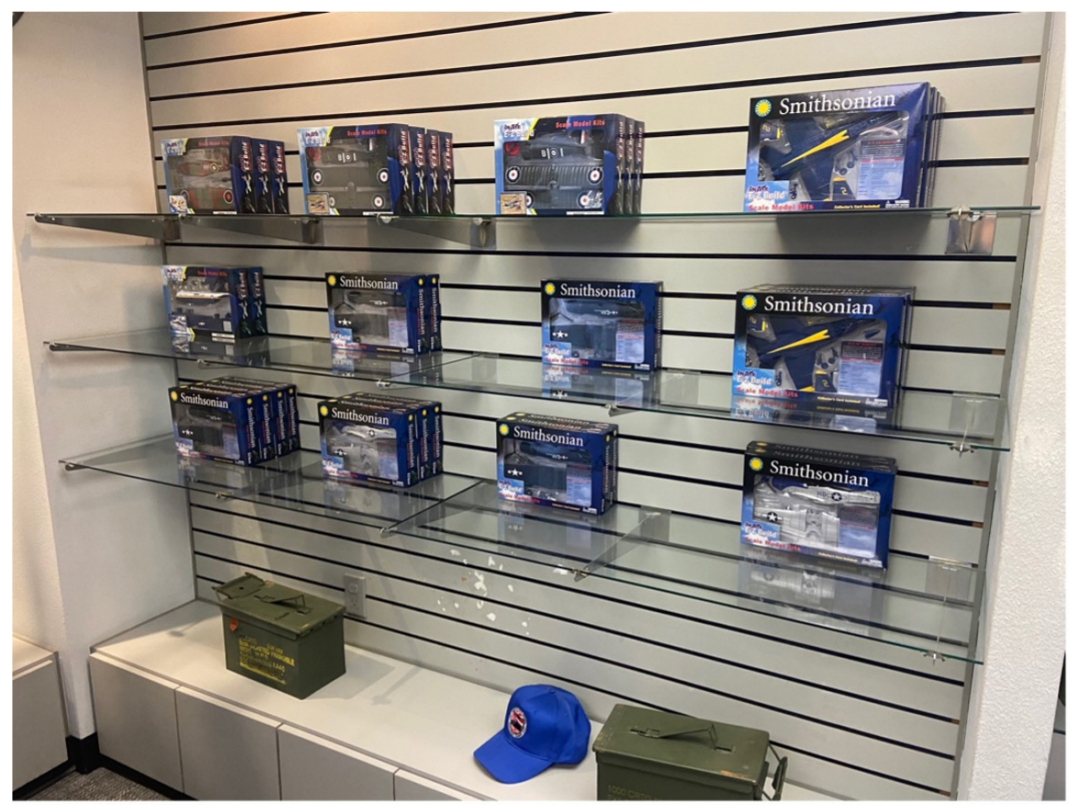

Figure 6. Model WW2 airplanes in gift shop, including Japanese Zero and Corsair. Photo credit: Cavanaugh Flight Museum 
If we focus solely on James's early experiences and claims, it's clear the museum is a significant, plausible source for all of them. Most of the relevant items were in areas of the museum where we know James spent considerable time-the gift shop and gallery areas at the entrance and adjacent to Hangar 1. Here James would've seen the Japanese battle flag prominently displayed (Figures 9 and 10), a variety of toy and model planes, including the Corsair and Japanese Zero (Figures 6, 7, and 8), and lots of pictures and artwork depicting $\mathrm{WW}_{2}$, including carriers and Corsairs in battle scenes (Figures 5 and 12). ${ }^{17}$ In the hangars, James would have seen the planes the Leiningers mentioned, and what they did not mention, namely the FM-2 Wildcat with a drop tank attached and B-25 and Spitfire drop tanks in the artifact areas of the museum (Figures 2, 3, 4).

The Canteen (Figure 13) is of particular interest since it was a room with tables set up with televisions displaying aviation videos, including WW2 videos. The Canteen is located at the entrance to Hangar 2. Today the room is a conference-style room used to display pictures celebrating the Cavanaugh Flight Museum, its history and planes.

Given the walk path that leads from Hangar 1 to Hangar 2 (see Figure 14), and the proximity of the Canteen to Hangar 2 (Figure $14 \mathrm{~A}$ and Figure 14B), it's highly likely James went into the Canteen. We know the kind of videos that were on display or available for viewing. It's plausible he saw portions of the aviation videos visitors could view there, including videos with WW/2 scenes. And we can't plausibly rule out that he saw a video that showed and mentioned something as specific as the Corsair. Videos of that sort were available at the time and commonly sold and shown at aviation museums, and the Corsair had been a prominent plane on display at the Cavanaugh. It's also plausible, given the amount of time James spent in high-traffic areas of the museum, that he heard visitors, employees, and perhaps his own father, use words he associated with the items he saw. He did not need to have any ability to read to absorb and retain information conveyed visually and audibly.

We can't prove James saw all of the items above and heard salient information about all of them. But a potent skeptical rejoinder doesn't need to prove this. The skeptical argument here is an inference from what we know. We know the general layout of the museum, and we 


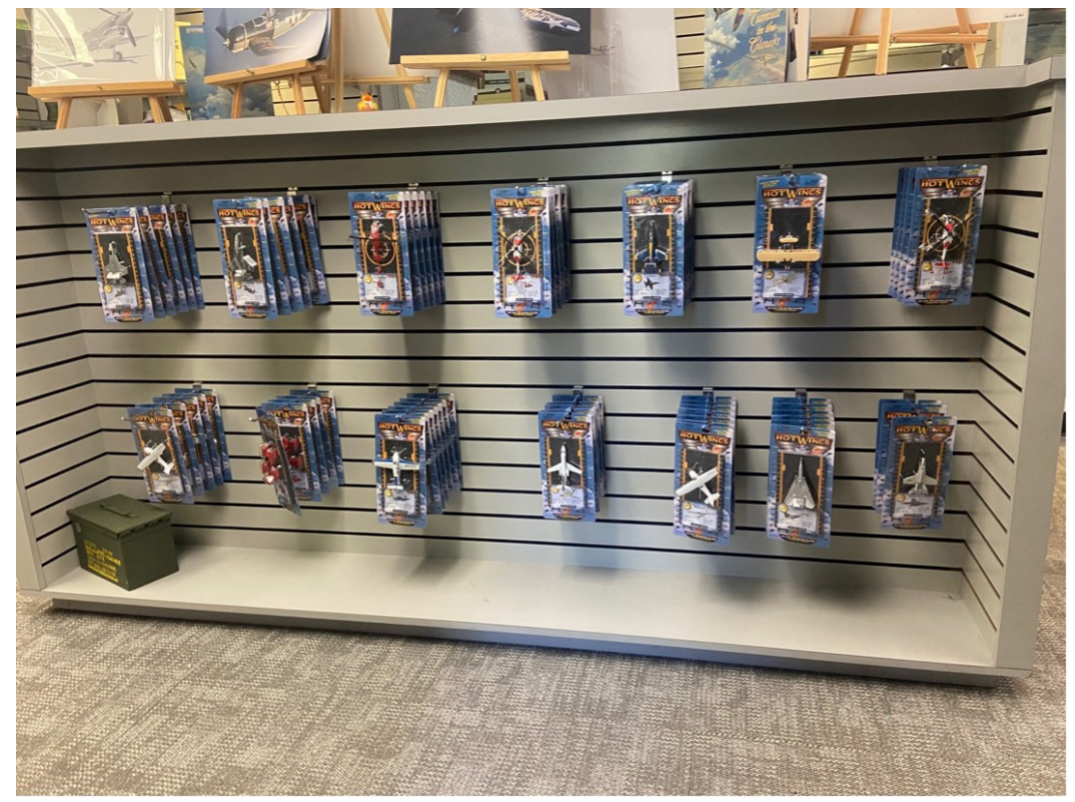

Figure 7. Toy airplanes in museum gift shop. Photo credit: Cavanaugh Flight Museum

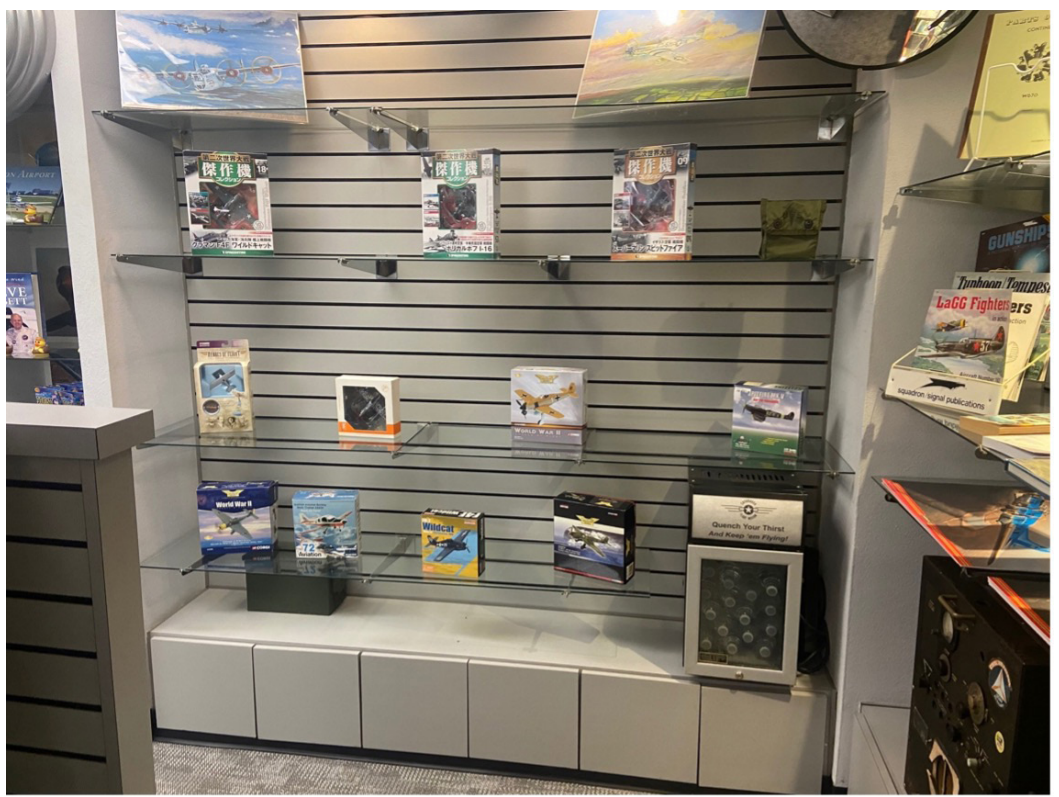

Figure 8. Toy warbird planes in museum gift shop. Photo credit: Cavanaugh Flight Museum 

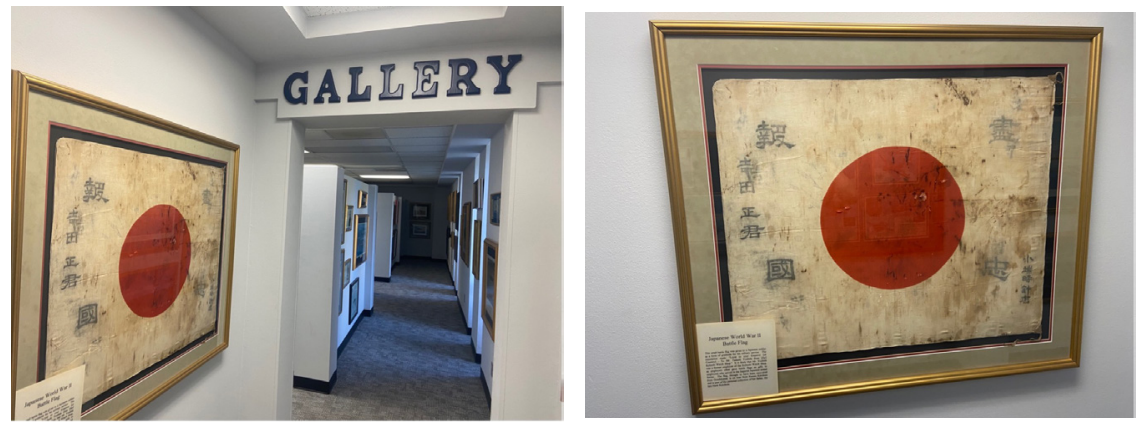

Figure 9. Japanese Battle Flag (side view). Figure 10. Japanese Battle Flag (front view). Photo credit: Cavanaugh Flight Museum Photo credit: Cavanaugh Flight Museum

Figure 11. P-51 Mustang at Cavanaugh Flight Museum. Photo credit: Cavanaugh Flight Museum
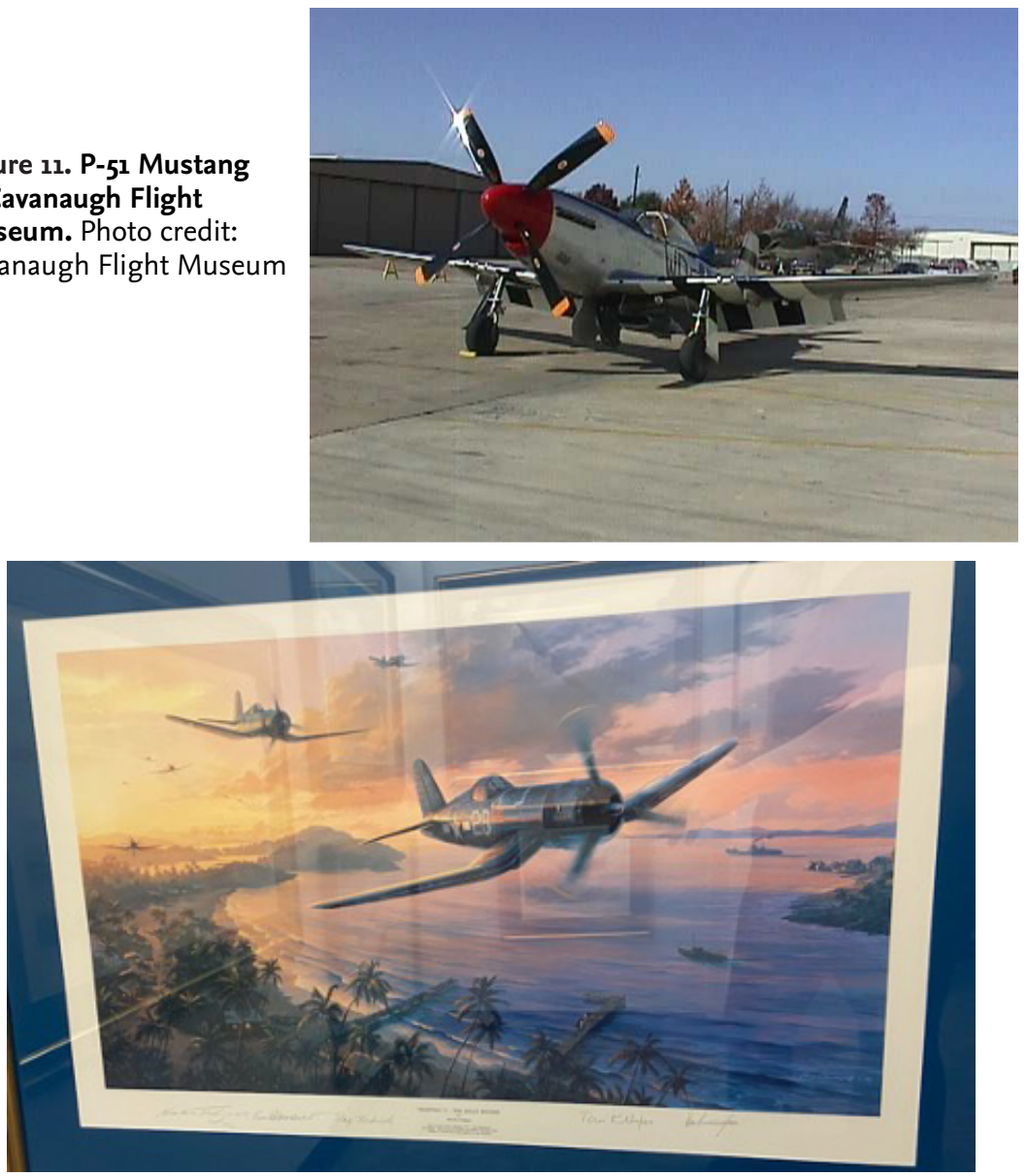

Figure 12. VF-17 Jolly Rogers flying Corsairs in Pacific Theater Battle (by Nicolas Trudgian). Photo credit: Cavanaugh Flight Museum 


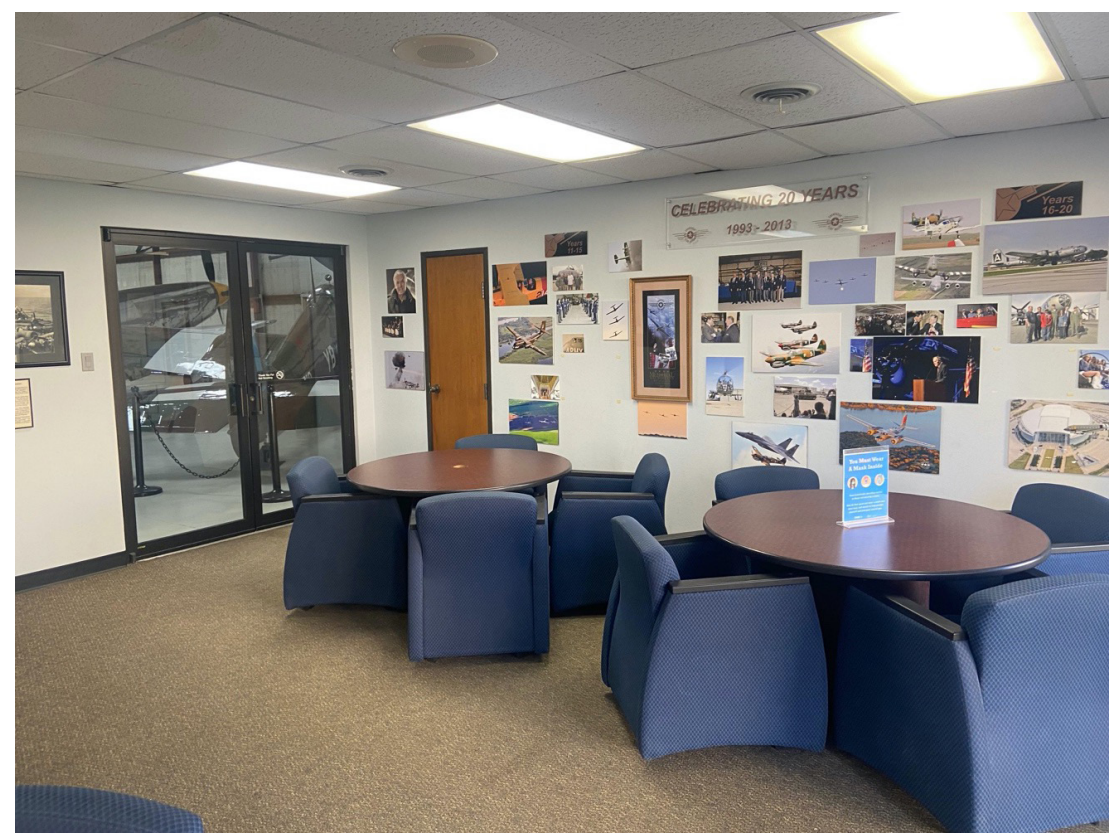

Figure 13. The Canteen. Photo credit: Cavanaugh Flight Museum

know what exhibits were on display and where they were located. We also know what kind of products were on display in the gift shop. And we know where James spent most of his time in the museum. So, it's probable that James saw most of the items if not all of the salient items and exhibits-for example, the specified hangar planes, toy/ model Corsairs in the gift shop, and the Japanese battle flag located in between the gift shop and the gallery. He made at least two trips to the museum in 2000 , each for a few hours. It's highly probable that he saw the items multiple times and for long periods of time, and in the company of other people.

Three things follow.

First, it's highly plausible that James's museum visits were the source of his ability to identify the Corsair plane, know a handful of warbird features, including their flying off boats, and to associate the Japanese with the symbol of the red sun. He would also be able to contextualize these facts in a wartime narrative, which included Corsairs in battle with the Japanese over islands.

Second, we have a very plausible, if not probable, ordinary 


\section{Gavanaugh Flight Museum Facility Map}

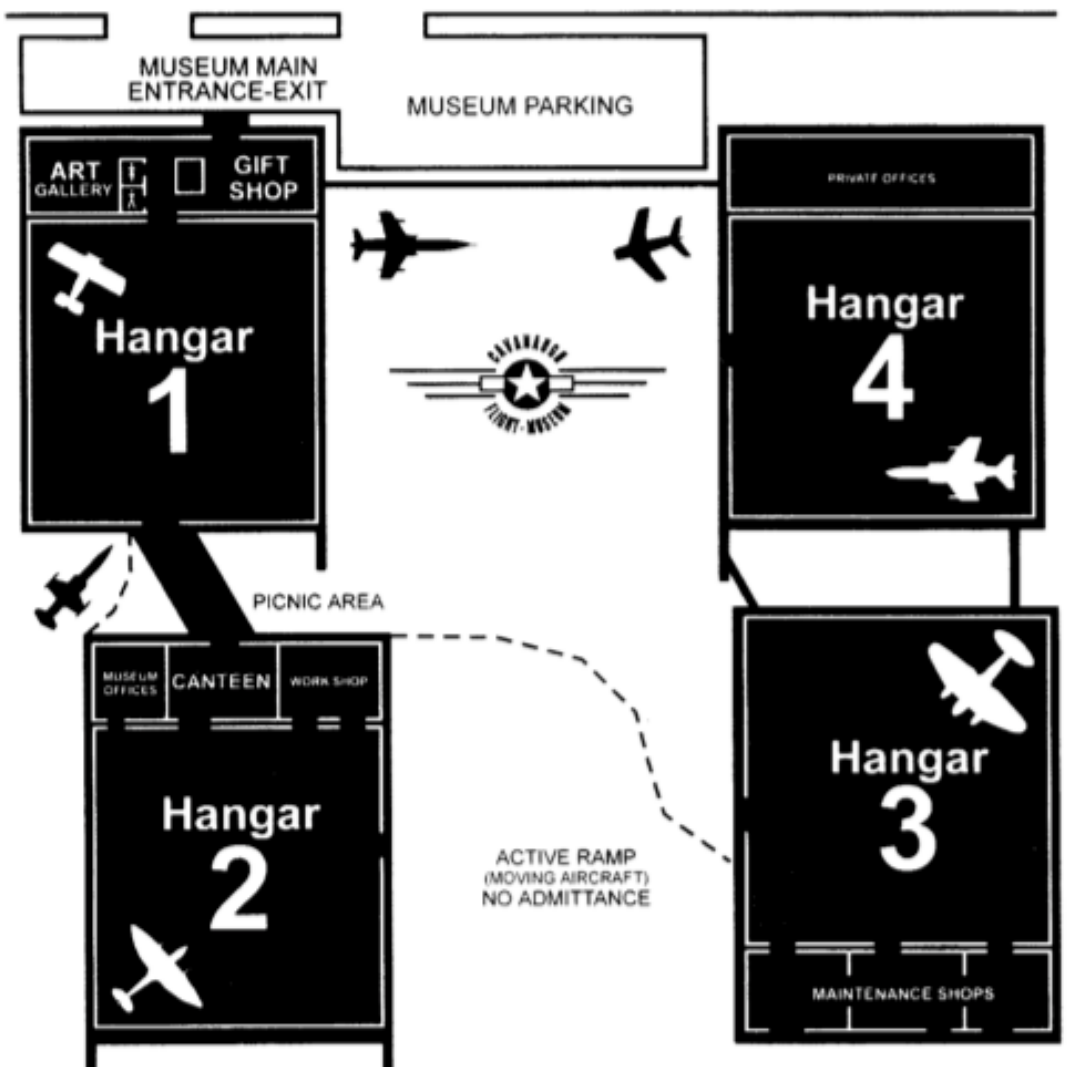

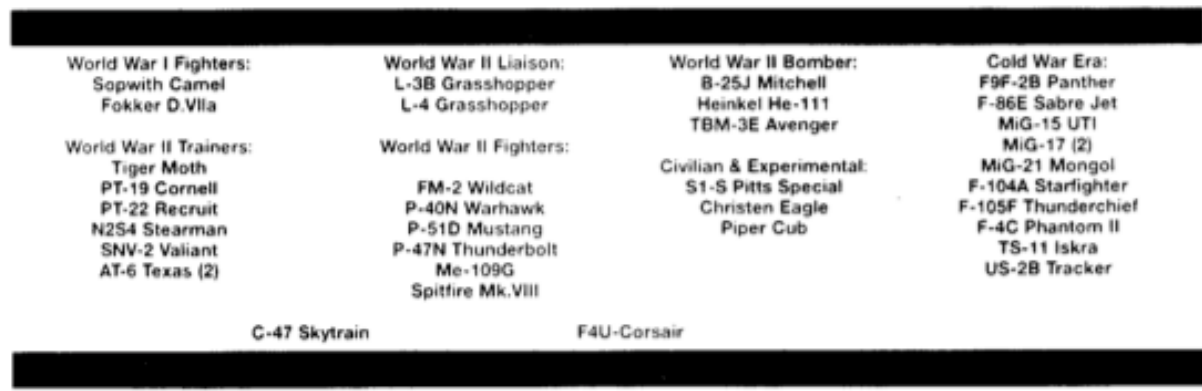

Figure 14. Cavanaugh Flight Museum Facility Map (Cavanaugh Flight Museum, 1999, inside front cover). Photo credit: Cavanaugh Flight Museum 


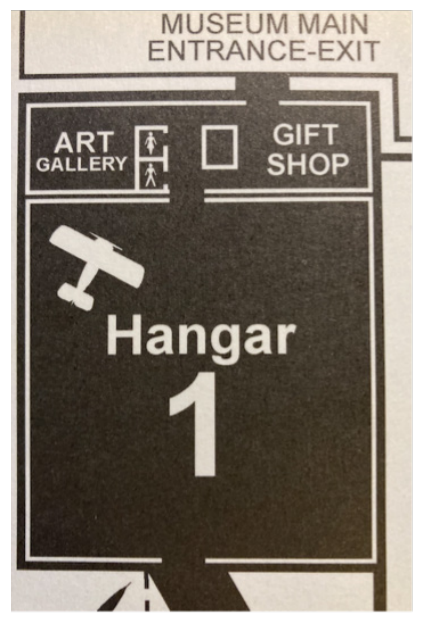

Figure 14A. Hangar 1 map. Photo credit: Cavanaugh Flight Museum

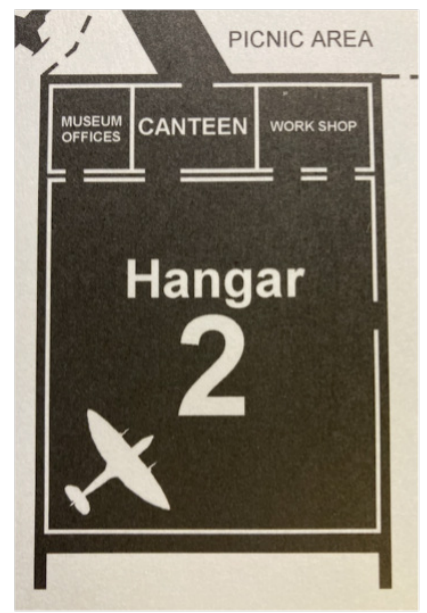

Figure 14B. Hangar 2 map. Photo credit: Cavanaugh Flight Museum

explanation for items \#4 and \#6 in Tucker's list of early-bird items (Table 1). And Tucker has not plausibly ruled out the museum, together with the Blue Angels video, as a source for items \#1, \#2, \#5, and \#7..$^{18}$

Finally, the Blue Angels video and Cavanaugh Flight Museum together provide a plausible, if not probable, source for nearly every item of knowledge the Leiningers attribute to James between March and September 2000 in their 2009 official account, as well as a plausible account of factors that contributed to the occurrence and content of his nightmares.

Based on the above, the skeptic is right to conclude that Tucker has not plausibly ruled out ordinary sources for the seven early-bird items he discusses, much less for the additional items the Leiningers attribute to James in their narrative as occurring between February and September 2000. Moreover, the skeptic is right to take the stronger position that ordinary sources do sufficiently explain the data in question, such that no reincarnation hypothesis need be invoked to account for the presumed facts in these early, significant stages of the Leininger chronology. ${ }^{19}$ 


\section{Other Potential Sources 2000-2003}

What ought to equally concern us are the sources James was exposed to but about which we have little or no knowledge. If the content of the Blue Angels video and the Cavanaugh museum flew under the radar of James's parents and Jim Tucker all these years, it's reasonable to think that more subtle sources of information might also have gone unnoticed. As the phenomenon of dark data in statistical reasoning reminds us, what we don't know matters.

For example, what was the content of the conversation with Charles Bond on the second visit to the Cavanaugh? What other comments or conversations did James pick up on in the context of immersing himself in WW2 planes and memorabilia for hours at the museum? Even the Leiningers acknowledge that at least one family member wondered whether James might have picked up something from the news that might explain his obsession with a crashing plane (SS, p. 57). Given that the national and international news had reported a dozen commercial plane crashes between February and July 2000, including the France Air Concorde crash that killed 105 onboard and Air Philippines in which 131 were killed, this concern is too easily dismissed in the Leiningers' own narrative. ${ }^{20}$

We should also consider that James's claims range over a period of several years, during which time we know he was exposed to an increasing number of sources related to aviation in general and $W_{W} W_{2}$ aviation and warbirds in particular. Here are just some of the potentially significant sources.

-Vintage Wings and Things, owned by David Jeansonne, was located in the Leiningers' hometown, in Carencro, LA, a suburb of Lafayette. This company had the same Corsair plane (N448AG) that in fall 2002 ended up in the Cavanaugh Flight Museum to replace their earlier Corsair that crashed in 1999. Jeansonne's Corsair was housed at the Lafayette Regional Airport until July 2000, and he would on various occasions roll the Corsair and his other vintage planes out for public display in Lafayette-for example, at the Sertoma Cajun Air Festival. ${ }^{21}$ The Leiningers report that James went to this airport on multiple occasions while the plane was there (SS, pp. $37,48)$, and we know James attended the Sertoma Cajun Air Festival (SS, p. 188). 
- James attended the Sertoma Cajun Air Show Festival, October 27-28, 2001 (SS, p. 188) held at Lafayette Regional Airport. At this festival, we're told James met with a few Blue Angels pilots. We don't know the content of these conversations or the extent of other conversations he had on this occasion or others, but these conversations would be potential sources of information he later exhibited, including his knowledge about WW2 and warbirds. The festival was a place where WW/2 buffs would gather, chat about vintage planes, and display warbirds, so the scope of potential sources of information from conversations he overheard or participated in is quite large. The event also included flight simulators especially designed as a children's attraction. ${ }^{22}$

The Leiningers do not indicate how many times James went to the Sertoma Cajun Air Festival between 2000 and 2006, just as they don't indicate whether James went to the Cavanaugh Flight Museum more than twice. But there is evidence that 2001 was not the only time James attended the festival (Figure 15). John Fallis-owner and restorer of vintage planes in Lafayette-informed me that he met James at the festival when James was between six- and eight-years-old (so, between 2004 and 2006), and the two had a lengthy conversation about warbirds. Fallis had his rebuilt P-40 warbird on display at the time, and James seemed to know a lot about this plane, though he told Fallis the Corsair was his favorite plane. ${ }^{23}$ Fallis said he remembers being impressed with James's technical knowledge of planes, which included how they were equipped with weapons. When Fallis asked James where he learned so much about vintage planes, James said, "Just reading." This was one of several occasions Fallis and James Leininger hung out and discussed vintage planes.

Although Fallis's conversations with James took place several years after the initial events in the Leininger chronology, quite possibly a year or so after the 2004 Primetime program, it's instructive in at least three ways. First, it shows that James attended the Sertoma Air Show more than once between 2000 and 2006, not surprising given his interest in warbirds. Second, it illustrates the kinds of conversations James was accustomed to having with veterans and warbird experts when he met them at public events, including this particular local festival. Finally, Fallis said that James's knowledge of vintage planes, at least by the 


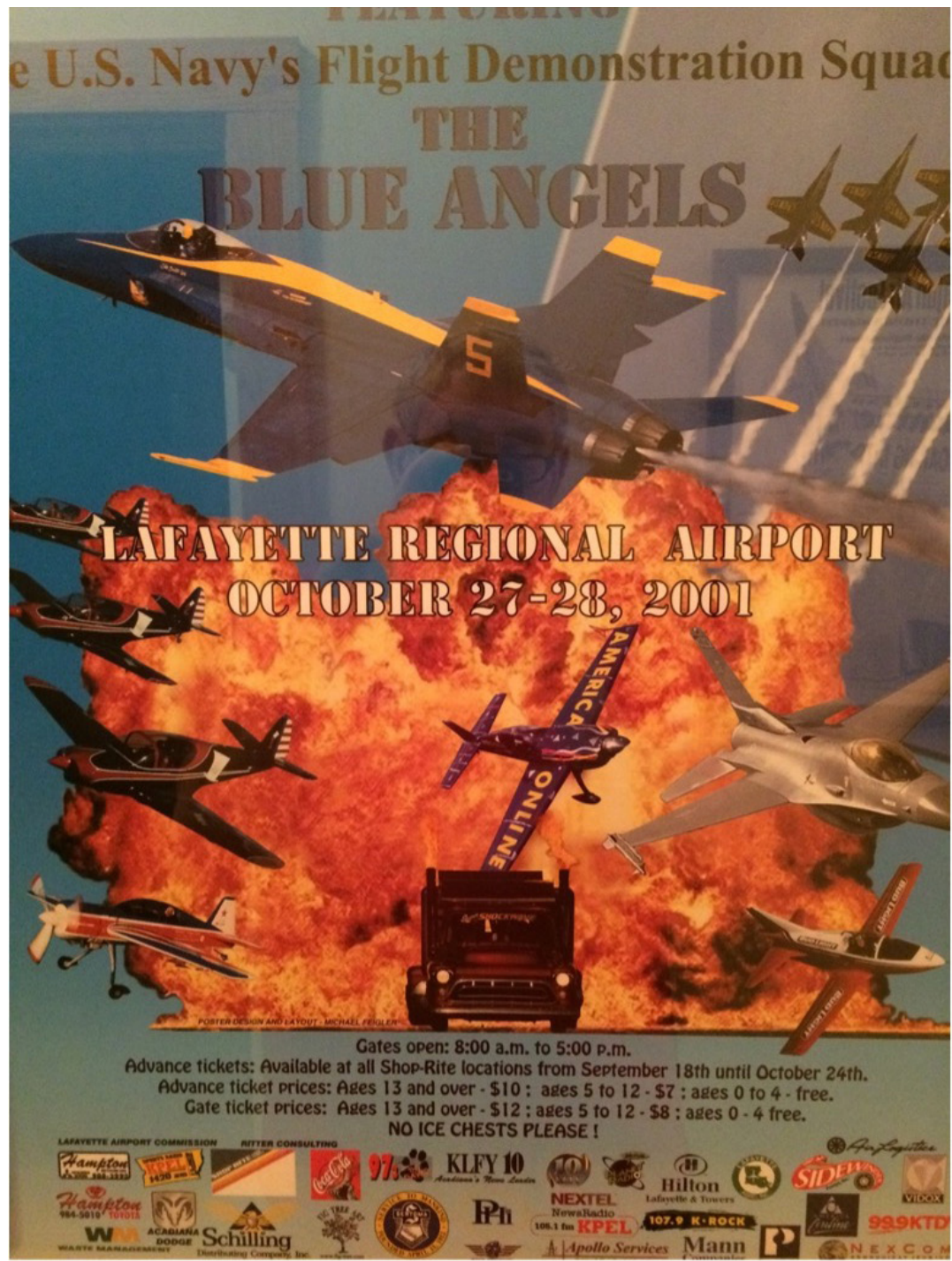

Figure 15. Poster-Blue Angels at the Sertoma Cajun Air Festival, October 27-28, 2001. Photo credit: Leon Labbe

time he met him, may very well have been informed by James reading Walk Around (Squadron/Signal Publications), a 1990s book series which featured technical details of warbirds, and which were sold at the Cavanaugh Flight Museum. ${ }^{24}$ 
- James viewed various $W_{W} 2$ related films over the years, some focused on specific fighter planes, including the 2002 A\&E documentary Battle Stations: Corsair Pacific Warrior. This particular film-to be discussed in Section 4-first aired in 2002 and covered details on the landing issues with Corsairs, archival footage of carrier landings and air combat with heavy flack, how Corsairs were used as napalm bombers, and specific lines James later repeated. It was preceded by an episode on the war in the Pacific. The Discovery channel had an ongoing series on warbirds beginning in the $1990 \mathrm{~s}$ and which featured an episode on the Corsair. Additionally, many Blue Angels videos produced in the 1990 os and which were available for viewing and purchase at aviation museums contained WW/2 information with archival footage.

-Other museum visits: In spring 2002 James visited the Lonestar Flight Museum for the filming of the $2002 \mathrm{ABC}$ program. James attended another aviation museum in 2004 which had W/W2 artifacts (Tucker, 2013, p. 82); this appears to have been the Nimitz Museum in Texas (SS, photos, p. 14). In summer 2002, the Leiningers vacationed in Hawaii (SS, p. 174) and stayed near Pearl Harbor. We don't know whether James visited any war museums or memorials during this trip. But given the extent to which his parents accommodated his interests in $W^{2} W_{2}$, it would be surprising if he had no exposure to $W W_{2}$ memorials and exhibits, which raises the reasonable question as to what he would've been exposed to in such situations.

When we look at these sources, we can't rule them out as plausible sources of information which shaped the Leininger narrative. One of the difficulties in this case is that we can't confidently distinguish between sources that confirm things James knew and sources that supplied James with information. Why? Because we have a broad range of known and unknown sources of information, claims evolving over several years, and-to be shown below-a deeply flawed chronology of events with significant gaps that make the narrative vulnerable to significant psychological confabulation. There is also a significant time gap in the Leiningers' chronology, roughly between early 2001 and spring 2002. The Leiningers say very little about what happened during this period, much less what James was exposed to which could have shaped his perspective. The Leiningers give every indication of 
supporting James's interest in airplanes and WW2, so it's unreasonable to think they changed their behavior and suddenly isolated him from salient sources like the ones outlined above. Regrettably, Bruce Leininger has repeatedly declined to answer my queries about the extent and dates of James's visits to various aviation museums and demonstrations.

If a few discovered sources, which Tucker and other researchers previously failed to acknowledge, change the face of the case in the ways I've shown, the possibility of further dark data, perhaps altogether inaccessible to us at this point, is a real concern. The likelihood of such untapped sources should not be ignored in the assessment of this case. What we don't know matters.

Finally, it's important to consider how various environmental factors the Leiningers mention in passing potentially illuminate James's wider psychological landscape. The family move in late February/early March of 2000 was stressful, and even Andrea Leininger's mother briefly considered that it played some role in James's nightmares (SS, p. 35). James also took trips to the Lafayette Regional Airport, usually to see his dad off on business trips every other week; this was also the occasion for James having outbursts about his father's plane crashing and bursting into flames (SS, pp. 36-38, 47-50, 76). James's nightmares intensified and he began verbalizing their content a week after visiting the Cajun Heartland Fair where he experienced aviation rides (SS, pp. 32-33). Tucker also doesn't pay much attention to any of these issues when considering psychological explanations. Even if he has dismissed them in his own mind, not addressing them gives the impression that they have been overlooked or dismissed without good reason.

Earlier I said that the presumed facts of the Leininger case are evidence for reincarnation only if:

(N) There are no additional facts that neutralize the evidential force of the presumed facts.

In this section I have argued that $(\mathrm{N})$ is not the case. Tucker has excluded or not acknowledged significant facts that severally and jointly raise the plausibility that the factual scaffolding of the Leininger case has ordinary sources in James's wider experience. These facts provide 
straightforward, ordinary explanations for nearly every item in Tucker's early-bird table, and there is no item in that table that Tucker can claim to have plausibly ruled out as derived from the sources outlined above. I've also assumed lan Stevenson's criterion of explanatory salience when dealing with potential ordinary sources of information.

Moreover, since these more obvious sources of information flew under the radar of the Leiningers and Tucker, we have reason to suppose that other sources shaped the evolution of the case in subsequent months and years, especially since James's subsequent experiences involve exposure to an increasing number of sources. Consequently, the presumed facts of the case cannot have the kind of evidential force Tucker attributes to them. Once we adjust the narrative of facts to include the material in this section, we have compelling evidencenot for reincarnation-but for how facts could give the misleading appearance of being evidence for reincarnation by excluding facts that point directly to ordinary explanations of seemingly extraordinary events.

\section{THE RELIABILITY OF THE LEININGERS' TESTIMONY}

The initial impressiveness of the Leininger case depends as much on including a whole range of presumed facts as it does on excluding facts concerning James's exposure to ordinary sources of information.

Earlier I said, the facts in this case are evidence for reincarnation only if:

(D) There are no significant grounds for doubting the presumed facts.

The presumed facts in the Leininger case include what James said, when he said it, descriptions of his behavior, and a variety of contextual details, including his parents's judgments about whether ordinary sources of information could have influenced his claims and behavior. There are also presumed facts concerning documents the Leiningers have presented, not simply facts about what the documents state but facts about what the Leiningers say about how and when they acquired the documents. All these facts are baked into Tucker's account and 
analysis of the case. But nearly all these facts are dependent on the testimony of Bruce and Andrea Leininger-two witnesses. Therefore, the presumed facts of this case have only as much credibility as the Leiningers' testimony has. And since Tucker's account and analysis is essentially tied to the testimony of the Leiningers, his favorable assessment of the case depends on the Leiningers being reliable witnesses, including reliable in their judgments about the plausibility of ordinary experiences supplying James with information. ${ }^{25}$

It's a basic principle of testimony that what people report about their experience is, all other things being equal, probably as they report them. So, it's entirely reasonable to accept what people tell us about their experience, unless we have overriding reasons to think their claims are false or their testimony unreliable-for example, due to dishonesty, asserting falsehoods, significant inconsistency, confabulation, or malobservation. In other words, we should trust people's claims about their experiences until we have reason not to do so. Testimony is prima facie reasonable, until other considerations defeat or override it.

In the case of the Leiningers, we have several different overriding reasons not to trust their testimony concerning the narrative of events and their interpretation of these events, including their repeated assurance that there is no possible way James could have known what he knew through any ordinary source. They are not reliable in these crucial ways and therefore not credible.

\section{Poor Judges of Plausible Ordinary Sources}

One area where the Leiningers lack reliability is in their judgment about the kinds of things James was exposed to at different points in the chronology of events and which plausibly shaped his experiences, claims, and behavior.

In Section 3 I gave six examples of James's aviation claims and behavior which the Leiningers thought were unusual, but each item is found on the Blue Angels video he regularly watched. The same video also contained imagery of a fighter plane being shot in combat and bursting into flames, as well as images of bombs dropping on land targets. Yet, the Leiningers are confident that they have ruled out this kind of exposure. Referring to the disturbing images James was 
experiencing in his dreams, Andrea said, "I kept thinking where is he getting this? What's he watching on television? But I was a stay-athome mom, so I know there wasn't anything that he was exposed to."26

In Section 3 I also examined six WW/2-specific claims the Leiningers attribute to James in the early months of the case and which they regard as inexplicable. I showed that all six claims involve information James would've been exposed to at the Cavanaugh Flight Museum. Yet, with reference to these claims, in the 2004 ABC Primetime segment, Andrea Leininger said, "I knew what he watched on television. I knew what stories I read to him. I'm a protective, first-time southern mother. There's no other place he could have been getting this information."27

Consider also how baffled the Leiningers were regarding some of James's crucial claims. When James identified a drop tank in March 2000, Andrea asked Bruce, "How would he know that?" adding that "he can't even say 'drop tank," and Bruce could only shake his head (SS, p. 17). Later when James said the Japanese shot down his plane, Andrea asked, "How did he know about the Japanese?" and Bruce replied, "I don't know. How the hell did he know about a drop tank?" (SS, p. 68). The next day James explains that he knew the Japanese shot him down because he could identify "the big red sun," a reference no less puzzling to James's family (SS, p. 70). They express similar amazement over James knowing the word Corsair and giving it as the name of his plane (SS, p. 79).

More recently, Bruce Leininger has said:

He knew the plane [Corsair]. How could James know the name of a World War II fighter aircraft, much less with certainty that it was the aircraft in the dream? And how the hell did James know they were launched from aircraft carriers? Nothing that he had ever seen or read or heard could have influenced him to have this memory. (Kean, 2017, p. 21)

Given everything that was available to James at the Cavanaugh and on the Blue Angels video, the claims the Leiningers discuss above are not the least bit surprising. What is surprising is that the Leiningers found them surprising. Either they were unaware of what James was exposed to or they egregiously misjudged the relevance of such 
exposures. Yet, they're adamant-Nothing ... could have influenced him. Their confidence is excessive and their language grandiose. We should be deeply suspicious of people who claim to know with certainty what they can't possibly know.

It's not as if the Leiningers haven't on occasion addressed the possibility that James's visits to the Cavanaugh influenced him. After acknowledging his visits to the Cavanaugh museum with his father, Andrea Leininger wrote:

The flight museum has refurbished planes in it from WWI, WWII, plus the Korean War, Vietnam, and then more modern military aircraft. There was no Corsair on exhibit at the time, and there were no videos of burning or crashing planes. Just large hangers with the aircraft from each era sitting out on display. It was about 4 months after the trip to the museum that James had his first nightmare. When the whole night terror thing started, we briefly considered the trip to the museum as a cause, but since he had been just a very young toddler, so much time had passed (four months is a long time in toddler years!) and none of what he was telling us could be traced back to that museum visit, we eliminated it as a possibility. ${ }^{28}$

Andrea Leininger provides two reasons for eliminating the museum as a possible influence on James's experience and source of the information he later conveyed. None of what he was telling us could be traced back to that museum visit, and so much time had passed between the visits and the beginning of the nightmares. The first premise is demonstrably false-nearly everything James said in the first several months can be easily traced to the Cavanaugh museum and/or the Blue Angels video. The second premise is irrelevant. There are many ways dreams, including nightmares, can incorporate material from the waking-state, and they can do so over varying periods of time. Moreover, in James's case, his initial nightmares came around the time toddlers first begin having nightmares, namely around age two. There's nothing unlikely about his first museum visit shaping his initial nightmares, especially since he was repeatedly viewing a video of a plane bursting into flames more proximate to the emergence of his nightmares. ${ }^{29}$

But what's most striking is what Andrea Leininger does not say. She says nothing about the Corsair planes in the gift shop, the Japanese 
battle flag with the big red sun, the drop tanks on display (on planes and in the artifacts hangar), the battle scene images in the gallery, or the Canteen where aviation and $W_{W} 2$ videos were viewable. She says nothing about the artwork which shows Corsairs flying over islands and engaged in battle scenes in the Pacific theater. The Cavanaugh was clearly not just large hangars with aircrafts on display. She assumes without justification that there were no videos of burning or crashing planes. Like Tucker, she incorrectly assumes that the only way James could have picked up the word Corsair was if there was an actual Corsair at the museum. And she is silent about the Blue Angels video purchased at the museum and which we know contained images of a plane on fire after being shot in combat.

The Leiningers have provided further examples of claims they say have "dumbfounded" them. One particularly important example is an incident Bruce has regularly cited since 2009, though it was not included in Soul Survivor. On Bruce's birthday when James was five-years old October 7, 2003-James reportedly said to his father, "Every day is like a carrier landing. If you walk away, you're okay." ${ }^{\circ 0}$ This particular anecdote has gained prominence in the retelling of their story over the years. Most recently, Bruce presented this incident as important evidence in his 2021 prize-winning essay for the Bigelow Institute of Consciousness Studies. Bruce wrote: "7 October 2003-Out for a walk on my birthday with James I was talking about the tough day l'd had. James said 'Dad, every day is like a carrier landing. If you walk away from it you are OK!' Again, this was not a 5 -year-old child speaking; it was an older soul" (Leininger, 2021, p. 16).

In the 2021 documentary The Great Beyond Revealed, Bruce said the following about this incident:

He knew things or was able to convey information that just dumbfounded us. One night l'd come home from a consulting day that was rather harsh. And we went for a walk around the block... He looked at me, and I was kind of commiserating with a three-year old, and he said "Well, Dad, every day is like a carrier landing, if you can walk away from it, you're okay." Huh? You have a threeyear grandson or child, is that what they tell you? (Honeywell et al., 2020, 0:18:13-0:18:56) 
As the Leiningers exhibit elsewhere, they have a very loose connection with facts in the retelling of their story over the years. Despite how impressive this incident was in Bruce Leininger's mind, he can't decide whether it took place when James was three or five years old - the version of the story in the 2021 documentary is inconsistent with the version in Bruce's 2021 BICS paper. ${ }^{31}$ The more serious problem, though, is that James's philosophical insight has a fairly obvious ordinary source which didn't show up on Bruce Leininger's radar. James's statement is found in a 2002 A\&E documentary on the Corsair plane. In Battle Stations: Corsair Pacific Warrior, WW2 Corsair pilot Colonel Archie Donahue said, "Each day in life is like a carrier landing. If you can walk away from it, you're in good shape." ${ }^{32}$ The A\&E documentary focused on the role of the Corsair in the war in the Pacific, and Donahue made his statement while discussing the difficulties of carrier landings.

We know James saw the Corsair documentary. It's the "History Channel program about Corsairs" the Leiningers admit James watched on a video tape (SS, p. 268). The Leiningers don't give the title of the video, but since they describe a scene uniquely characteristic of the program, there's no doubt they're referring to the Battle Stations Corsair episode. Although they're not clear about when James watched the tape of the program, we can establish a timeframe. The documentary first aired on December 26, 2002 on the History Channel network. ${ }^{33}$ Since James made the philosophical statement to his father on October 7, 2003, he had nine months to acquire a tape of the program and watch it repeatedly and absorb its content, even if he didn't see it when it originally aired. ${ }^{34}$ Yet, Bruce Leininger doesn't as much as even acknowledge that the statement he invests with such evidential value appears on the video.

Other examples could be provided, but these are more than sufficient to raise a tough and serious question: If the Leiningers have failed to notice or acknowledge just how many of James's claims and behaviors came from just two video sources and the Cavanaugh Flight Museum, are they in any position to give a reasonable assurance that any claim they have attributed to James doesn't derive from something he saw or heard somewhere? I think the answer here must be no. 


\section{Distorting Facts Concerning the Death of James Huston, Jr.}

Another vital tier of the Leiningers' story is their attempt to show that the facts concerning Huston's death match what their son had to say about Huston's crash - that is, what James said about the crash he was experiencing in his dreams and had apparent waking state recollections of. But their attempt to verify James's claims involves a distortion of the facts surrounding Huston's death. ${ }^{35}$

In their effort to get at the facts surrounding Huston's death, the Leiningers rely on primary documents (composed in 1945 shortly after Huston's death), secondary source documents in the form of veteran recollections and narratives composed decades after the war, and interviews Bruce Leininger conducted with several WW2 veterans who participated in the mission in which Huston was killed. However, Bruce Leininger's handling of these sources produces a highly misleading narrative of Huston's death.

The U.S.S. Natoma Bay Aircraft Action Report (hereafter, AAR) for March 3, 1945, provides a very detailed description of the circumstances of Huston's crash. The Leiningers refer and allude to this document (SS, pp. 175-76, cf. 239, 242), and they reproduce a diagram of the aircraft strike on Chichi Jima contained within the document (SS, p. 12, photos section). But they never quote directly from the AAR. On the face of it, this is odd. The AAR provides a detailed description of Huston's crash and was composed proximate to the actual event. And it's the source for material in other documents on which the Leiningers rely. Since the Leiningers spend at least a third of their book trying to reconstruct the circumstances of Huston's death, it's surprising that the content of this document wasn't included in their book, except when parts of the AAR's account appear in other documents.

Return briefly to the Leiningers' narrative of Huston's death based on the claims they attribute to their son. Huston's plane was supposedly hit in the engine and immediately burst into flames. Huston was trapped inside the burning plane and trying to extricate himself from the cockpit. Then it crashed in the water at Iwo Jima. Little James reportedly said, Huston was still alive both before impacting the water and after, struggling to extricate himself from the plane. According to Andrea Leininger, "After his plane was hit in the engine, it crashed nose first 
into the water. From what my little James told me after his nightmares, he was alive in the plane when it went into the water, and was kicking to try and break out the canopy to escape the sinking plane. ${ }^{36}$ The book omits this detail and focuses instead on the plane bursting into flames after being hit in the engine and James apparently being trapped in a burning plane quickly descending toward the water, but where it's at least unclear is whether his struggle to extricate himself also took place after the plane hit the water. ${ }^{37}$

The Leiningers claim that the after-action reports are "muddled and confused" (SS, p. 239), but they never show this. Their criticism looks like a subtle concession to the lack of confirmation primary source documents provide for some of the claims they attribute to James. But their dissatisfaction with the after-action reports is their stated reason for seeking out alternative sources of information about Huston's crash, sources that as it happens turn out to be more amiable to confirming James's airplane-crash narrative.

Ultimately, Bruce Leininger relies on the testimony of four veterans from a different carrier who were part of the Chichi Jima mission in which Huston died. The men were members of the VC- 83 squadron on the U.S.S Sargent Bay and who flew the TBM Avenger bombers in the strike on Chichi Jima. Bruce Leininger interviewed John Richardson, Bob Skelton, Ralph Clarbour, and Jack Durham. Durham said the plane "took a direct hit on the nose" and he could see "pieces falling into the bay" (SS, p. 241). Richardson allegedly said Huston's plane was "hit in the engine by what seemed to be a fairly large shell" and "there was an instantaneous flash of flames that engulfed the plane" (SS, p. 244). Skelton is reported as saying he saw Huston's hit and the plane "blew up" (SS, p. 249). Clarbour said he saw Huston's plane hit "right in the engine" and there was an "instantaneous flash of fire" before the plane dove and crashed into the harbor (SS, p. 250).

There's something odd about this from the vantage point of the Leiningers' own approach to documentation. In trying to establish the details surrounding Huston's death, the Leiningers indicate that they "couldn't rely on anything that had the informal taint of old memories," and so they marginalize the unofficial log Natoma Bay veterans compiled in the 1980s-the so-called Blue Book-and privilege the official government documents typed in 1945 "right after the battle and 
the debriefing, when everyone's memory was fresh" (SS, p. 166). So, the Leiningers felt they could not rely on the recollections of the Natoma Bay veterans in the Blue Book composed three to four decades after the war, but they could rely on the recollections of a few elderly veterans from a different squadron on a different carrier six decades after the war. The testimony of the Avenger pilots does confirm certain details of James Leininger's crash narrative. But the Leiningers give a decent reason for privileging primary source documents over veteran recollections. In the light of the Leiningers' reluctance to trust the "informal taint of old memories," it's hard to see why they would think they could rely on the memories of Avenger pilots nearly sixty years after the war, except that their testimony confirmed aspects of James's airplane-crash narrative which the primary source documents could not confirm.

The main problem, though, isn't the Leiningers' apparent methodological inconsistency. It's that the AAR contradicts important aspects of their narrative, and the Leiningers have conveniently omitted these details. Whether deliberate or not, ignoring the AAR allows the Leiningers to bury important disconfirmations of claims they attribute to their son.

The AAR indicates that on March 3, 1945, eight pilots from the Natoma Bay (flying FM-2 Wildcat fighter planes), together with eight TBM Avenger bombers from the U.S.S Sargent Bay, attacked the harbor at Chichi Jima, about 160 miles north of Iwo Jima. The FM-2 pilots were the escort for the TBM bombers, which had a three-person crew in each bomber: pilot, turret gunner, and radioman/bombardier/ventral gunner.

Here is the relevant summary of the circumstances of Huston's death provided in Section XII of the document. I quote the material in full.

All aircraft recovered to the west toward the entrance of the harbor. Heavy anti-aircraft took them under fire from each side of the harbor. It was thought to be 3 inch batteries. Lt (jg) J.M. HUSTON was apparently hit by this fire as he approached the harbor entrance. None of the other pilots saw a hit and his airplane was not on fire, but it suddenly nosed over into a 45 degree glide crashing into the water, exploding and burning. At the time the plane nosed over, it was at about 1500 feet altitude and was estimated to have crashed while 
making about 175 knots. There was no wreckage left afloat and only a greenish yellow spot on the water marked the crash. There was no evidence of a survivor and it is believed that it would have been impossible to survive the crash and resulting explosion. (Position of crash is indicated on diagram). The position of the crash is in enemy territory but possibilities of compromise of classified material is considered improbable. He may have been hit and killed by light fire as no one reported observing any damage to the plane; most of the bursts in the vicinity where he crashed were from 3 inch (or equivalent) guns. (Italics are mine). $3^{8}$

The AAR does not confirm details the Leiningers wish to confirm. More importantly, it actually disconfirms crucial parts of their narrative. It thereby also raises considerable doubt about the reliability of the testimony Bruce Leininger attributed to the four TBM Avenger pilots he interviewed nearly six decades after the incident.

First, the report states that witnesses saw Huston's plane suddenly nose over and go into a 45-degree glide and crash into the ocean. It exploded and burned on impact. Who saw this? The Leiningers would have us believe that only the Avenger bombers Bruce Leininger interviewed witnessed Huston's death (SS, p. 242). But this is poorly reasoned and patently false. Bruce only interviewed a small fraction of the over thirty men who participated in the mission; he can't rule out that individuals he didn't interview were the source of the information in the AAR, including members of Huston's VC-81 squadron. Eight FM-2 Wildcat pilots flew off the Natoma Bay on the mission in which Huston died. Seven returned. Of those seven, Bruce Leininger apparently interviewed only two of them-Jack Larsen and Bob Greenwalt. Larsen didn't see what happened to Huston, and the Leiningers say nothing about what Greenwalt saw or didn't see, which means it's doubtful he could confirm the details Bruce Leininger was looking to confirm.

It's not difficult to figure out the source of the information in the AAR. Since the Natoma Bay AAR would've been filled out by the Intel officer for the VC-81 aboard the Natoma Bay, either someone in the VC-81 saw what is reported in the AAR or one or more members of the VC- 81 heard radio communications from the TBM Avenger pilots of the VC-83 describing what happened to Huston. 39 But if the latter, it certainly wasn't the Avenger pilots Bruce Leininger interviewed, unless 
they changed their story after 1945 , because the AAR contradicts what they had say about Huston's crash. The report is explicit: the plane was not on fire and no one reported observing any damage to the plane. If the veterans Bruce interviewed were the source of the information in the AAR, that report should indicate that Huston's plane was damaged by a direct hit to the engine and propeller and the plane burst into flames. But the AAR says the opposite..$^{\circ}$

Second, although no one witnessed the plane being hit-not the same as no witnesses to what happened-the obvious inference from the circumstances of the mission is that Huston was hit by anti-aircraft fire. But the report leaves open whether some part of the plane was disabled by anti-aircraft fire or whether it was Huston himself who was hit by artillery that penetrated the cockpit and killed him instantly. If the latter, it would have been impossible for Huston to have been kicking and otherwise trying to extricate himself from the plane, even before his plane hit the water. If the former and he was still alive, he had at the most between 10 and 20 seconds to try to release the canopy before the plane hit the water. While the report is consistent with Huston being alive and struggling to bail out, it's also consistent with anti-aircraft fire instantly killing him. It also doesn't indicate that either of these two scenarios is more likely than the other. Thus, the AAR cannot be invoked to confirm this part of the Leininger narrative. ${ }^{41}$

Third, the report further conveys the belief that it would have been impossible for anyone to have survived the crash and resulting explosion. Sensible enough given Huston's speed on impact-it would have been like slamming into a brick wall at 200 miles per hour. Not surprisingly, no wreckage was observed, only a greenish yellow spot on the water where the plane hit. The discoloration on the water surface was likely sea dye marker used to help rescuers locate the crew of downed planes. The dye would've been in the life raft. In the FM-2 Huston was flying, the raft would've been stored in a compartment behind the pilot's head and accessible from a hatch outside the plane. The flotation vest Huston would've been wearing likely had the dye as well. The discoloration on the surface of the water, appearing so quickly, implies that the impact violently and suddenly breeched the cockpit. The crash was catastrophic. Even if Huston was alive before the plane crashed-and that's not more probable than not-the impact 
killed him. He did not die by drowning. So, the AAR disconfirms a crucial component of the Leininger narrative.

The AAR confirms at the most four of the claims attributed to James concerning Huston's death: Huston flew off a boat named Natoma Bay, he was shot by the Japanese, his plane crashed in the water, and he had some association with a person named Jack Larsen. It disconfirms three fairly specific claims: the plane was on fire (prior to hitting the water), Huston was alive after the plane hit the water and struggling to get out of a sinking plane, and the plane crashed at Iwo Jima. And two claims are at best neither confirmed nor disconfirmed: The plane was hit in the engine/propeller, and Huston was alive after the hit and struggling to get out. So, of the nine claims attributed to James about the circumstances of Huston's death, only four are confirmed, and only one of these-the Jack Larsen claim-is idiosyncratically true of Huston. ${ }^{42}$

The Leiningers buried the details of the AAR. Instead, they quote from other primary and secondary documents (for example, the VC-81 War Diary) which exclude the claims that contradict their narrative-the plane was not on fire, no damage was observed, it was possible that the plane crashed because anti-aircraft fire killed Huston in flight, and it was not possible for Huston to have survived the crash. They also focus on the testimony of four pilots from a different carrier who participated in the mission and whose account-nearly sixty years after the facthappens to fit James's description of events. This from Bruce Leininger who "felt he couldn't rely on anything that had the informal taint of old memories" (SS, p. 166).

We should ask ourselves, what's more probable? That the primary source documents, composed within days of the incident, are incorrect about crucial details, including those that would be essential to any decision to attempt a rescue of Huston, or four elderly veterans misremembered some of the details of one sortie they flew on one particular day in a war nearly six decades in the past? Of course, even if we had an independent reason to trust the reliability of the Avenger pilots so long after the event, we would still have conflicting testimony. And when the best sources don't agree, we must acknowledge we don't know what happened. And if we don't know what happened, there is no known fact to serve as a confirmation of James's claims. ${ }^{43}$ 


\section{NARRATIVE REDACTION}

Another set of closely allied problems that impugn the credibility of the Leiningers concerns narrative redaction. The Leiningers have presented various iterations of their story since 2002. Over the years, they have changed important details concerning what James said and when he said it, either omitting or adjusting the content of his claims or the dates on which he allegedly made the claim. Consequently, there isn't one James Leininger story. There are many versions of the story. Since they are inconsistent with each other, they can't all be true. The Leiningers' propensity toward narrative redaction further impugns their reliability-in the telling of any story, you need to consistently get the important stuff right.

Of course, not all inconsistencies are equally egregious. So, let me be clear at the outset that the inconsistencies l'll canvass below are not innocuous or benign. Far from it. First, they suggest that the Leiningers are not sure about what James said and when he said it, especially with respect to some of the most important claims they attribute to him. At best we have no way to adjudicate these multiple and incompatible iterations of their story. Second, most of the redactions-for instance, as they appear in their 2009 book Soul Survivor-were made after the Leiningers had done considerable research and had a robust knowledge of James Huston. It's concerning that the Leiningers made changes to their story in the light of facts they later discovered. And it's suspicious that the changes were fortuitous - they resulted in making James's claims better fit the historical record concerning Huston's life and the circumstances of his death. Such conceptual gerrymandering easily produces a deceptive appearance of impressiveness.

\section{Three Forms of Narrative Redaction}

The official Leininger narrative involves three kinds of redactions: (a) chronological redactions-changes to the dates when James allegedly said certain things, (b) claim omissions-the official account in Soul Survivor excluding claims the Leiningers have elsewhere attributed to James, and (c) claim adjustments-the official 2009 account in Soul Survivor altering what James reportedly said or the Leiningers adjusting their interpretation of claims subsequent to the publication of their book. 
A significant illustration of b-type redaction includes Andrea Leininger's claim in July 2005 (above) that James told her Huston didn't die from the crash but died by drowning after he failed to extricate himself from his sinking plane. It's antecedently unlikely that Huston survived the crash, and the AAR sensibly claims it was believed to have been impossible. So, if we trust the AAR, that testimony counts against the veracity of James's claims here. And if we doubt the accuracy of the AAR document, why appeal to it at all to support other claims? But the Leiningers' official version of the story omits this highly detailed version of James's description of the crash. In this way, a clearly disconfirmed claim is omitted from the official narrative.

There are two very significant redactions of the c-type, one concerns what James said about the Corsair and the other to what he said about Iwo Jima.

In their book, the Leiningers reproduce a conversation they allegedly had with James surrounding the content of his nightmares. Since he had been describing a "little man" being in a plane crash, they asked him what kind of plane the little man flew. James said a Corsair, and he indicated that he flew it off a boat, which a few sentences later he identifies as the Natoma (SS, p. 78-80). The context strongly suggests that James is the little man and he was telling his parents that the plane he crashed and died in was a Corsair, and that he had flown this plane off a boat called Natoma. The Leiningers interpreted James to mean exactly this for at least two years (SS, pp. 113, 144, 152, 224). Tucker also acknowledges this as the suggested narrative in the $2002 \mathrm{ABC}$ program. ${ }^{44}$ But subsequent to the publication of their book, the Leiningers have said that James never explicitly said his Corsair took off from the Natoma or that he was shot down while flying a Corsair (B. Leininger, 2009).

This is quite misleading. While it may be true that James never explicitly said he flew a Corsair off the Natoma Bay and died while flying one, what matters is what James meant. ${ }^{5}$ But whether we are talking about children or adults, we rely on a person's explicit words and what they imply given contextual details. Which is exactly what the Leiningers rightly did until it became inconvenient to their evolving narrative. We may never know what James said or meant, but we can't ignore the context in which he made the claims attributed to him. In the portion of dialogue between James and his parents reproduced in 
their book, it's contextually clear that the Leiningers were asking James about the plane he was flying in his nightmares and in which he crashed. His answers to their questions are naturally interpreted to mean that he was flying a Corsair when he crashed and that he flew the Corsair off the boat he called the Natoma. And Bruce and Andrea Leininger thought this is what he meant for at least two to two-and-half years. ${ }^{46}$

As far as I can see, the only relevant fact that guided the Leiningers' reinterpretation of James's claims is their later learning that Huston did not crash in a Corsair but that he did test fly a Corsair before joining the Natoma Bay (SS, p. 226, 269-270). The more general claim-Huston flew a Corsair — can be made to fit the facts concerning Huston's life. The more specific claims-flew a Corsair off the Natoma and crashed and died flying a Corsair-do not fit the facts. But, given the absence of any independent reason to prefer interpreting James as intending one thing as opposed to the other, it looks as if subsequently discovered facts motivated the reinterpretation of the earlier claims with the result that it created a better fit with the facts. The facts thereby confirm rather than disconfirm the reincarnation narrative the Leiningers wish to perpetuate. In a game of darts, this would be similar to painting the target around the spot where the dart has landed so that the dart is located in the bullseye, then claiming to have hit the bullseye. No one can deny that the dart fits perfectly in that space, but how it ended up in that spot matters.

A more important redaction concerns James's important Iwo Jima claim. Prior to the publication of their book and as early as 2002, the Leiningers state that in late November 2000, James pointed to an ariel view of Mount Suribachi at Iwo Jima and said, "Daddy, that's where my plane was shot down."47 The image James pointed to was in a book on the Battle of Iwo Jima (Wright, 1999, p. 3), which Bruce had recently purchased for his father. However, in Soul Survivor, we get a different version of this story. The Leiningers alter the claim they attribute to James. James now allegedly said, "Daddy, that's when my plane was shot down" (SS, p. 104). Bruce Leininger and Jim Tucker interpret this to mean his plane was shot down during 'Iwo Jima operation', not at the island of Iwo Jima (Tucker, 2016, p. 204, Table 1). Tucker attributes the change to Bruce correcting a decade-long incorrect memory about what James said (Tucker, 2013, p. 75). 
While the redacted statement attributed to James is vague, at least the historical record doesn't clearly refute it. But that advantage comes at a cost. Misremembering for nearly ten years what James allegedly said on a vital point in the story doesn't induce confidence in the reliability of one's testimony, especially since the Leiningers regard the Iwo Jima claim as one of the more significant claims they attribute to James (SS, p. 104; cf. B. Leininger, 2021, p. 10). In early versions of the story, James even clarifies his comment at Bruce's request and says, "My plane was shot down there, Daddy." 48 Also, Bruce initially discounted Huston as the pilot in his son's narrative because the facts he discovered in September 2002 didn't fit James's claims. For example, Bruce reasoned, "Huston wasn't even killed at Iwo Jima. He was killed on a mission a couple of hundred miles away, at a place called ChichiJima" (SS, p. 141)—a strange observation if James never said that the location of his crash was Iwo Jima. Most importantly, though, the change to what James said about Iwo Jima comes only after Bruce Leininger learned that Huston's plane crashed at Chichi Jima, not at Iwo Jima, but that he nonetheless crashed and died during the Battle of Iwo Jima. Conveniently, the redaction results in attributing to James a claim the facts don't obviously disconfirm.

Additional evidence for chronological redaction comes from comparing Carol Bowman's version of the Leininger story and the Leiningers' version of their story.

According to Soul Survivor, Bowman didn't get involved in the case until winter 2001, at which time Andrea wrote her and they had correspondence about James's nightmares (SS, pp. xii, 116-117). After March 2001, they didn't have further correspondence or discussions until March 2002 (SS, pp. xiii, 117, 121-125). At that time, Bowman reached out to Andrea regarding the prospects for doing the $2002 \mathrm{ABC}$ TV show. In her "Forward" to the Leiningers' book, Bowman says that when she reconnected with Andrea Leininger in spring 2002 for the first time in about a year, James had provided new details since their previous interactions. James had "remembered the type of plane he flew [Corsair], the name of the aircraft carrier [Natoma], and the name of one of his pilot friends [Jack Larsen]" (SS, p. xiv). Elsewhere Bowman adds the Iwo Jima claim as occurring after their 2001 correspondence (Bowman, p. 2010, p. 55).49 
The problem here should be transparent. If-as the Leiningers say-Carol Bowman had her initial correspondence with Andrea Leininger in winter 2001, then one of two things must be true: either the items Bowman lists as new details were not new or those items must have happened between winter 2001 and spring 2002, not between August and November 2000 as the Leiningers claim in their book. Since Bowman lists the new revelations from James as occurring between 2001 and 2002 in her "Foreword" to the Leiningers book, the inconsistency is internal to Soul Survivor. Something isn't right about the Leiningers' story at this point. ${ }^{50}$

The Leiningers' inconsistency concerning when Bowman got involved in the case further obfuscates the matter. In their book, the Leiningers say winter 2001, and Bowman agrees. ${ }^{51}$ But in the Great Beyond Revealed documentary, Bruce Leininger indicates that Bowman first got involved in August 2000, at least a month before James gave the name Jack Larsen..$^{52}$ It's unclear why Bruce Leininger would present a narrative in which Bowman enters the picture during summer 2000 , given that he had written a book in which he says she first appeared nine months after that date.

\section{The 2003 Chronology of Events}

Further evidence of large-scale redaction in the Leininger narrative comes from a detailed, four-page document I acquired from Lucinda DeWitt, the daughter of Natoma Bay Association historian John DeWitt. John DeWitt was a key player in Bruce Leininger's attempt to acquire historical documentation to verify his son's claims, as he supplied Bruce with primary source documentation about the Natoma Bay and James Huston (SS, pp. viii, 137, 142, 166-169, 175-176). The document is titled "A Chronology of Events James M. Leininger and James M. Huston, Jr." I'll hereafter refer to this document as the 2003 Chronology. Lucinda DeWitt informed me that Bruce sent her and/or her father this document in fall 2003, seven years before the Leiningers published Soul Survivor. It's written in the first person, with Bruce Leininger as the ostensible narrator providing a detailed chronology of events from February 2000 to September 2003.53

There are serious and troubling discrepancies between the official 
timeline published in 2009 and the 2003 Chronology. I list some of the more significant ones here.

Claim: James identified himself (James) as the little man in the plane and said he was flying a Corsair, and that he flew off a boat.

Official 2009 Chronology: August 27, 2000

2003 Chronology: Late September-October 2000

Claim: He flew off a boat named Natoma.

Official 2009 Chronology: August 27, 2000

2003 Chronology: Late October-November 2000

Claim: Jack Larsen flew with me.

Official 2009 Chronology: October 5, 2000

2003 Chronology: Late October-November 2000

Contextual Detail: Initial Bowman and A. Leininger correspondence Official 2009 Chronology: January-February 2001 2003 Chronology: July-August 2000

There are a few things worth noting here.

First, there are two consistent features of the above discrepancies. They all involve important facts of the case, and they include the three most important facts of the case: Natoma Bay, Jack Larsen, and Carol Bowman's involvement. And the official chronology places each of these facts at a later date than the 2003 Chronology, as little as about a month and as great as six to nine months. The later the date when James makes the claims attributed to him, the more opportunity there is for ordinary sources to shape his claims. Not only because there are more opportunities for exposure to sources, but his verbal skills would have been more developed and so also his capacity for internalizing information, and eventually he would have had reading skills.

Second, consider the Bowman factor. According to the 2003 Chronology Carol Bowman got involved six to nine months before the Leiningers' book says she got involved..$^{54}$ Not only are the two accounts incompatible, the difference is significant in the wider context. Bowman's advice to the Leiningers was to tell James his experiences were of events he had experienced before. This would strongly suggest and easily instill a past-life narrative. As the Leiningers explain, "Carol 
advised Andrea to tell James that what he was experiencing were things that had happened to him before, that it was now over, and that he was safe" (SS, p. 117). As Bowman explains it, "I told the Leiningers that James was remembering a past life death, and I reiterated the techniques in my books: acknowledge what James was going through as a literal experience and assure him that he is was now safe, that the scary experience is over" (SS, p. xiii).

Regardless of when (on a calendar date) Bowman got involved, the crucial issue is whether she gave her advice to the Leiningers before or after James began making apparent past-life claims. I've already shown how this problem arises in the official narrative when paired with Bowman's account of events. It's even more explicit in the 2003 Chronology. Here James's explicit and implicit claims about a past life occurred after Bowman instructed James's parents to present the reincarnation narrative to him as fact, whereas the book's chronology brings her into the case after James allegedly made ostensible past-life claims.

But even if Bowman entered the picture in winter 2001, the explicit reincarnation claims attributed to James came later. Tucker says "By the time he [James] was three, he had told them [his parents] that before he was born, he was a pilot who flew from a boat. His plane got shot in the engine by the Japanese, he crashed in the water, and that's how he died" (Tucker, 2013, p. 64). And Bruce Leininger estimates the date when James said this to be September 1, 2001, which means James would have been three-and-a-half years old. ${ }^{55}$ So, even if we accept the chronology in Soul Survivor, James's explicit reincarnation claims come many months after the Leiningers had been inculcating this narrative in James.

James's past-life claim is an utterly unsurprising claim for a three-year-old to make given his immersion in WW2 imagery and the suggestion of a past life having been explicitly given to him repeatedly for at least half a year. The official narrative conceals this by introducing Bowman only after James had spoken of the Corsair, Jack Larsen, Natoma, the Japanese shooting his plane down, and his plane crashing at Iwo Jima. This clearly masks how Bowman and the Leininger family (wittingly or unwittingly) might've guided the construction of the reincarnation narrative James subsequently verbalized. 
There are reasonable allowances we should make for error and narrative discrepancy. But the quantity and quality of the Leiningers' timeline inconsistencies far exceeds what is rationally permissible. The 2003 chronology was composed in 2003, years before the book, whenin the words of the Leiningers- "everyone's memory was fresh" and they wouldn't have had to rely on "the informal taint of old memories" (SS, p. 166), and long before the Leiningers had thrown away or misplaced their contemporaneous notes. Moreover, a sequence of unintentional mistakes still undermines the reliability of testimony, especially if the mistakes are numerous and involve important facts. Finally, Bruce was ostensibly writing the 2003 summary for John DeWitt, a historian and acquaintance at the time. The four-page chronology of events gives every indication of having been meticulously prepared by someone who appreciates historical accuracy and who has given due diligence to accuracy and detail.

\section{The "Natoma" Veridical Claim}

In Soul Survivor, the Leiningers say James gave them the word Natoma on August 27, 2000, when they inquired about the name of the boat his plane flew off of. Bruce Leininger claims he conducted an Internet search that same night and located information on a WW/2 escort carrier named the Natoma Bay (SS, p. 79-80). The information was from the Dictionary of American Naval Fighting Ships. Bruce allegedly printed out the information and retained the document which has the website URL and date-stamp of $08 / 27 / 2000$ in the footer..$^{56}$

Next to the Bowman factor, the most controversial discrepancy between the official 2009 narrative and the 2003 Chronology concerns the date and circumstances of James giving his parents the word Natoma. The discrepancy here raises a serious concern about the veracity of this part of the Leiningers' story.

In the 2003 Chronology, the Natoma claim allegedly took place in late October/Early November 2000, not August 27, 2000.

Late October-November 2000

More details

Key Items:

1) After several attempts and numerous tries to understand 
what he was saying we finally got a word "NATOMA" from him. It resulted in finding that there was a Natoma Bay and that it had been a WWII Escort Carrier that had served in the Pacific.

2) James gave us the name Jack Larson and said Jack flew with him. ${ }^{57}$

This is no mere discrepancy; it's a glaring and disturbing one.

First, if the Leininger's official story and Jim Tucker's retelling of it is correct, then the 2003 Chronology contains a surprising kind of error. Bruce Leininger regards the Natoma claim as one of three pillars of the case. And unlike many of the other things he attributes to James, he didn't have to rely on his memory to accurately locate this event in his chronology. If the official account is correct, Bruce had the Natoma Bay document on hand with a timestamp that memorialized the dateAugust 27, 2000. He didn't have to rely on his memory.

Second, the 2003 Chronology doesn't make any mention of the Internet printout. Of course, that chronology also specifically places James saying Natoma in late October/early November of 2000, followed by the opaque note that James's dropping the name Natoma "resulted in finding that there was a Natoma Bay and that it had been a WWII Escort Carrier that had served in the Pacific." But no mention of the website printout, which is surprising since Bruce was ostensibly trying to document evidence for the Natoma Bay Association historian John DeWitt.

Third, in his 2016 case report Tucker doesn't list Natoma as an early-bird claim, despite the timestamped printout. That's because the early-bird claims in his report are based on what was documented in the 2002 unaired ABC Strange Mysteries segment, and the Natoma claim and its alleged supporting document were not included in the program. Tucker claims producer Shalini Sharma explained to him that this bit of evidence might have been excluded because other producers judged it was too weak as evidence. This suggests someone associated with the production at least knew about the document. In which case it's odd that when the production crew assisted the Leiningers with trying to locate the mysterious Jack/John Larsen/Larson (Tucker, 2013, p. 74, cf. SS, p. 138) they ignored the crew of the Natoma Bay and instead looked elsewhere and located a naval pilot named John M. Larson who had 
no connection with the Natoma Bay. ${ }^{8}$ This is especially bizarre since the Natoma Bay veteran Leo Pyatt allegedly told Bruce in December 2000 that a Jack Larsen served on the Natoma Bay, and in January 2001 Bruce printed out a list of the crew of the Natoma Bay killed in action in WW2 from the Battle Monuments Commission website (SS, pp. 140, 150). The list included the name of pilot James Huston, Jr., the only crew member killed while the Natoma Bay was supporting operations at Iwo Jima. These facts were known nearly a year-and-a-half before the filming of the Strange Mysteries program.

Recall also that Andrea Leininger did not present the Natoma Bay discovery to Carol Bowman in their initial correspondence. Bowman herself places the Natoma Bay discovery as one of the new developments in the case which she learned about when she re-established contact with Andrea Leininger in spring 2002 (SS, p. xiv; Bowman, 2010, p. 55). If James dropped the word Natoma after the initial Bowman correspondence and the initial correspondence took place in winter 2001, then James would've had to have given the name Natoma after Winter 2001 but before spring 2002 when Bowman reconnected with Andrea. In that case, James could not have first provided the name Natoma on August 27, 2000.

Finally, in their book and in various interviews, the Leiningers describe James as giving the word Natoma with ease. Given his age, this is unlikely. Quite sensibly, in the 2003 Chronology he only gives his parents the word "after several attempts and numerous tries to understand what he was saying." ${ }^{59}$ This is more realistic, but it doesn't engender confidence that the Leiningers even correctly heard what James said. Did he say Natoma or Sertoma (the name of the Lafayette Air Festival)? Did conflate Sertoma and the Natchez (a boat he rode while in New Orleans, SS, p. 58) or some other word? Did he utter nonsense? Who can say? And that's the point. When the Leiningers tell us that James said the name of his boat was Natoma, they are giving us their best guess at what they think he said. Seeing as the Leiningers get so many important details wrong, there's no good reason to trust that they got this detail right. And the degree of inconsistency surrounding the Natoma claim is more than enough to justify a thorough-going skepticism about this feature of the case. We don't know what word James uttered and we don't know when he uttered it. 


\section{TUCKER'S ANALYSIS RE-EXAMINED}

We're now in a position to carefully consider how the problems raised in previous sections undermine Jim Tucker's analysis of the case. In Tucker's 2016 report, he presents seven early-bird items:

1) "Mama, before I was born, (a) I was a pilot, and (b) my airplane got shot in the engine, and (c) it crashed in the water, and (d) that's how I died."6o

2) Died in the Battle of Iwo Jima

3) Nightmares of (a) plane crashing on fire and sinking and (b) being unable to get out.

4) Flew a Corsair

5) Plane flew off a boat

6) His plane was shot down by the Japanese

7) Corsairs got flat tires when they landed

Each of these, Tucker claims, was documented before Huston was identified. For each of these items, Tucker provides the source of information - the Leiningers - and the alleged verification of the match with Huston, together with additional qualifying comments for items (2) and (4). Tucker claims that reincarnation provides the best explanation of these items and that they are evidence for reincarnation.

In the light of what l've shown in the previous sections of the paper, we should be highly skeptical of Tucker's analysis and conclusions.

One serious problem is that Tucker's reasoning assumes that for each of the above items, he is reporting a claim indisputably made by James prior to the identification of James Huston and that there are facts sufficient to confirm that the claims match Huston's death or some feature of Huston's life. This is simply not true. We can apply what we've seen in previous sections to show this.

\section{Disconfirmed Claims: Items (1), (2), and (3)}

The facts disconfirm some of the items in Tucker's list, and so they cannot plausibly be said to match Huston's life. These are items (1), (2), and (3).

Yes, Huston was a pilot, his plane was shot down, and it crashed in the water. These highly general claims are (unsurprisingly) correct. But ( 1 ) and (3) include more specific claims-(1d), (3a), and (3b). The 
Leiningers attributed to James the claim that he (as James Huston) died by drowning after his plane crashed in the water. That's suggested in the wording of ( $3 b)$, and it's how the Leiningers interpret how in "that's how I died" in (Id). But the historical description of Huston's crash and accompanying commentary in the Natoma Bay aircraft action report make it highly improbable that Huston survived the impact. Moreover, if, as the Leiningers explain, James actually intended to state that his plane was on fire before it hit the water, the aircraft action report also contradicts this. So, of the six specific claims contained in (1) and (3), significant evidence disconfirms three of them. Since the veracity of James's narrative crucially depends on the details of Huston's death as James allegedly described them, the disconfirmations here are significant. ${ }^{61}$

(2) is clearly false. Huston did not die in the Battle of Iwo Jima, and he's not listed among the fatalities in that battle. Of course, James never said or implied that he died in the Battle of Iwo Jima. Prior to the publication of their book, the Leiningers said James pointed to an arial view of Iwo Jima and said that's where his plane crashed. That claim is also demonstrably false. We know Huston died $240 \mathrm{~km}$ (=149 miles) north of Iwo Jima, in Futami Harbor at the island of Chichi Jima, an altogether different island in the Bonin island grouping. James's claim is false. Full stop. ${ }^{62}$

Tucker bases his attribution to James on an interpretation of Bruce Leininger's correction of a decade-old false memory, a redaction the Leiningers made while writing their book. They changed their account of what James said to "That's when my plane was shot down" (SS, p. 104). They even altered what James said after his father asked him to clarify what he meant-from "My airplane got shot down there, Daddy" to "That's when my plane got shot and crashed" (SS, p. 104, cf. Tucker, 2016, p. 201). Like the Leiningers, Tucker interprets James's redacted claim to mean the time period in which his plane crashed. ${ }^{63}$ Apart from the dubious nature of the redacted claim, Tucker's interpretation is otherwise unjustified. Moreover, if he purports to be analyzing the early-bird claims as documented in the 2002 ABC program, he should state the claim as it was attributed to little James before the Leiningers had identified Huston. The actual early-bird claim is demonstrably false, and Tucker's parsing of what James said is without warrant. 


\section{Ambiguities and Redactions Masking Further Falsehoods: (4) and (7)}

The Leiningers' book makes it clear that, for a few years, they had interpreted James's claims about flying a Corsair to be a reference to the plane he was flying when the Japanese shot him down and he died. Moreover, the reproduction of the conversation in which James Leininger allegedly said he flew a Corsair (SS, p. 78-79) contextually implies he flew a Corsair off the Natoma Bay (false) and died flying a Corsair (false). For reasons discussed earlier, this was a plausible interpretation of James's claims given the context. The Leiningers later rejected it only because they discovered that Huston was not shot down while flying a Corsair and did not die in one, but he at least test flew one. Since they had decided on Huston as the previous personality, they retrofitted James's claims to this more mature narrative. But regardless of the reasons for the redaction, Tucker should state the claims as they were attributed to James prior to the identification of the previous personality. James indicated the Japanese shot him down when he was flying a Corsair and that he died flying a Corsair, both of which are false.

Item (7) does not concern Huston, except indirectly since Huston test flew the Corsair while he was with the VC-301 squadron in April 1944 prior to joining the VC-81 and serving on the Natoma Bay. The problem with this claim is that it is ambiguous. It's either a claim about something that was true of the Corsair and other WW/2 planes or something that was true of Corsairs in contrast to other $W W_{2}$ planes. If the former, the claim is true, at least when suitably qualified (see below). If the latter, the claim is false. Hence, the ambiguity straddles the line separating a claim that is easily knowable through ordinary means or easily disconfirmed.

Flat tires and collapsing landing gear were a common problem for WW2 fighter planes that had to make carrier landings. It wasn't uniquely true of Corsairs. ${ }^{64}$ This point needs emphasizing since there seems to be considerable confusion about it among people who discuss this case. Tucker cites an unnamed Air Force historian he didn't personally interview in support of the claim "Corsairs bounced when they landed, leading to flat tires" (2016, p. 204). The cited interview clip does not imply that flat tires were unique or especially true of Corsairs, 
and there's no evidence for that. While a deck bounce can cause flat tires, statistical data would be needed to show that it led to more flat tires with Corsairs than other warbirds, especially since this problem appears to have been linked to inexperienced pilots flying the Corsair. ${ }^{65}$ Most importantly, though, the Corsair bounce problem was resolved when the oleo struts were redesigned in early 1944. The $\mathrm{F}_{4} \mathrm{U}-1$ Corsair Huston tested with the VF-301 in April 1944 already had the redesigned oleo struts. Huston had probably heard about the bounce problem in earlier Corsair models, but he would have tested the redesigned Corsair after the bounce problem had been fixed. ${ }^{66}$

James's apparent knowledge about Corsairs getting flat tires is standard information on Corsair and other W/W 2 videos, especially ones that discuss naval fighter planes. For example, it's mentioned in the Corsair Battle Stations video discussed earlier. These videos also mention how the Corsair was redesigned during the war, the kind of detail a toddler is likely to miss. James gives no indication of being aware of the characteristics of the specific model of Corsair he would have test flown had he been Huston. His claims about the Corsair are what we'd expect from a toddler who had viewed videos or heard conversations about carrier landings, but who lacked a nuanced understanding. His claims are not what we would expect from someone who experienced flying a Corsair or who had a more conceptually developed understanding of WW2 warbirds.

\section{Dubious Confirmation: (1 $\mathbf{b})$}

Tucker's list also includes at least one item with a dubious confirmation. The only evidence for (lb)_-Huston's plane being hit in the engine-is the alleged testimony of the Avenger pilots Bruce Leininger interviewed. But, as argued earlier, their testimony is inconsistent with the narrative provided in Natoma Bay aircraft action report and which the Leiningers excluded from their book. We simply don't know that Huston's plane was hit in the engine. This isn't even probable given all the evidence. Maybe it's true. We just don't have overriding reason to suppose that it is. So, the facts do not all things considered confirm this early-bird item. 


\section{Plausible Alternative Explanations for Hits and Misses}

So, what does this leave us with?

The only claims attributed to James that are indisputably true of Huston are four: (1a) — he was a pilot, (1c) - his plane crashed in the water, (5)-he flew his plane off a boat, and (6)-His plane was shot down by the Japanese. But these claims are highly general and true of thousands of other pilots killed in WW2. So, it's unsurprising that they should fortuitously turn out to be true of Huston. The disconfirmed claims are the more specific ones. That James gets all these wrong, or that we're in no position to say whether they are correct or not, is quite telling. This outcome is exactly what we would expect from a fiction narrative. Whether we select a random dream we have or the narrative of a Stephen King novel, we're bound to find something that's true, especially very general truths, but the specifics are where we can expect to find falsehoods or claims so disconnected from reality that we can neither confirm nor disconfirm them. James's narrative of the plane crash in his dreams is utterly banal, in both its matches and misses. It's exactly what we would expect from a flight of imagination, not the real flight of a real WW/2 pilot. The only thing that is extraordinary is that anyone would think otherwise.

This is especially the case when we consider that his dream imagery has very plausible ordinary explanations in known exposures that the Leiningers and Tucker have not acknowledged. The Blue Angels video and his visit to the Cavanaugh Flight Museum were more than sufficient to supply him with the idea of being a pilot and the imagery of flying a Corsair fighter plane off a boat, being shot in combat with the Japanese, his plane catching on fire, and the plane crashing in the water. And the imagery of being trapped in a sinking plane is hardly one that exceeds the imaginative capacities of a two-year old. Even the timing of the origin of the nightmares is what we would expect given mainstream developmental psychology.

Moreover, even the overt reincarnation narrative in ( 1 ) has an obvious explanation. Based on the evidence presented earlier, James said (1) when he was around three and a half. As such, it has a quite pedestrian explanation: His parents gave him the narrative framework. 
The Leiningers followed Carol Bowman's advice (beginning in February 2001) and began telling James that his nightmare experiences were of something that had happened to him before (SS, p. 117). We have no evidence that James affirmed that he had lived a past life prior to his parents suggesting this to him. And that's true even if we rely on the official 2009 chronology. Tucker's analysis ignores the temporal priority of Bowman to the reincarnation narrative that subsequently seemed to be part of James's self-understanding.

\section{Reassessment of Tucker's Table of Early-Bird Claims}

In Table 2 below, I present a breakdown of twelve distinct and specific early-bird claims Tucker attributes to James in the seven items examined above, together with Tucker's regarding them as a match with historical facts.

TABLE 2

Tucker's List of Early-Bird Claims/Verifications 2002

Match with Huston

1) I was a pilot. Yes

2) I flew a plane off a boat. Yes

3) The Japanese shot my plane down. Yes

4) My planed crashed and sank in the water. Yes

5) My airplane got shot in the engine. Yes

6) I died because 4) and 5). Yes

7) My plane crashed on fire. Yes

8) I could not get out of my sinking plane. Yes

9) I died in the Battle of Iwo Jima. Yes

10) I flew a Corsair. Yes

11) Corsairs got flat tires when they landed. Yes

12) James's metanarrative claim "before I was born, I was a pilot, and my airplane got shot in the engine, and it crashed in the water, and that's how I died." 
Tucker would have us believe that James made the twelve claims above before Huston had been identified and that (1)-(11) match the life of Huston, and that (12) indicates James's awareness of having lived a past life. He says this is evidence for reincarnation. But the latter is not true, and it's not true because the matches to Huston's life are illusory. The appearance of genuine matches in Table 2 (and Tucker's original seven items) depends on the following logically dubious maneuvers:

— treating disconfirmed claims as confirmed-(7), (8), and (9)

—replacing disconfirmed early-bird claims with non-disconfirmed redacted claims - (9) and (10)

—relying on unwarranted verifications-(5)

-relying on ambiguity to force-fit matches with Huston-(6), (9), (11), and possibly (7).

- Ignoring the temporal priority of parental influence via Bowman shaping the reincarnation narrative attributed to James's self-understanding-(12).

Only four of the twelve claims-(1), (2), (3), and (4)-are indisputably known to be claims James made and which clearly match the life of Huston. By themselves, these four claims are hardly surprising and wouldn't merit any serious attention. But when they are placed in the context of other more specific claims presumed to be matches, the result is a more robust narrative. In that narrative, the four claims that would otherwise be unsurprising matches now seem like elements in a narrative that resists ordinary explanation.

Tucker has created the appearance of something impressive. There's no doubt that his narrative will prove psychologically impactful to some people, but in point of logic the reasoning is dubious. First, everything in the list is very plausibly explained by a combination of chance coincidence and exposures to the content of video(s), WW2 exhibits and memorabilia, and Bruce Leininger's book on Iwo Jima. Nothing more is needed to explain any of this. Second, the more specific claims are actually unwarranted, either because they are disconfirmed 
or because they are not sufficiently confirmed. Third, in speaking of James's verbalizations of the content of his nightmares prior to August 27, 2000, Tucker says "James indicated that they were memories of events from the past" (2016, p. 201). He thereby implies that James's reincarnation self-understanding contained in (12) occurred before August 27, 2000. This is both unwarranted and false, even by Tucker's own admission elsewhere (Tucker, 2013, p. 64). And after mentioning the events of December 2000, he says, "With the ongoing nightmares, James's parents eventually contacted Carol Bowman" (Tucker, 2016, p. 201). He thereby suggests that James made several of his important past-life claims before Bowman entered the picture, but this is highly dubious for reasons discussed earlier. Consequently, Tucker's big-picture narrative deceptively gives the reincarnation hypothesis an appearance of plausibility which it simply does not have.

If we strip the fictional scaffolding away from Tucker's list of earlybird claims, we get a very different table of claims and match-withHuston outcomes (Table 3).

In Table 2, eleven claims allegedly match Huston, and (12) provides the reincarnation framework for the 11 claims. However, in Table 3 only four of the eleven match Huston. Moreover, the matches are all very general claims, whereas the specific claims do not match Huston, and in at least one case we don't know if the claim is veridical or not. And once we acknowledge that Bowman conveyed a reincarnation narrative to the Leiningers and they passed it on to James before he made any past-life claims, the ostensible reincarnation claim in (12) is plausibly interpreted as something instilled in James. This is a considerably less impressive outcome, even if we have no way to assess how evidentially strong the results are in Table 2.

For reasons adduced earlier, I think we have good reasons to prefer Table 3 over Table 2. But even if we had no overriding reason to prefer Table 3 over Table 2, it's at least clear that we have no non questionbegging reason to prefer Table 2 over Table 3. So, either there's good reason to prefer Table 3 over Table 2 or we have no overriding reason to prefer either table. Since Tucker's case for reincarnation depends essentially on the robust narrative in Table 2 and we at least have no reason to prefer that narrative to the alternative robust narrative in Table 3, Tucker's case for reincarnation fails. 


\section{TABLE 3}

Alternative List of Early-Bird Claims

\section{Item}

Match with Huston

1) I was a pilot.

Yes

2) I flew a plan off a boat.

Yes

3) The Japanese shot my plane down.

Yes

4) My plane crashed and sank in the water.

Yes

5) My airplane got shot in the engine.

?

6*) I died by drowning (after my plane crashed).

No

$\left.7^{\star}\right)$ My plane was on fire before crashing into the water.

No

$\left.8^{\star}\right)$ I was trapped in my sinking plane and tried to escape but couldn't.

No

$\left.9^{\star}\right)$ My plane crashed at Iwo Jima.

No

10*) I was flying a Corsair when I crashed and died.

No

$\left.{ }_{11}{ }^{\star}\right)$ Corsairs had a unique problem of getting flat tires when they landed.

12) James metanarrative claim "before I was born, I was a pilot, and my airplane got shot in the engine, and it crashed in the water, and that's how I died."

His case for reincarnation also fails because there is a most plausible ordinary explanation for the veridical claims in Table 2 and all the claims in Table 3. We have a straightforward explanation of the content and occasion for James's nightmares, as well as why James gets correct what he gets correct, and why he gets incorrect what he gets incorrect.

From this vantage point, we can see why Tucker's dismissal of alternative explanations in (2016) fails. He dismisses an explanation of this case in terms of "knowledge acquired through ordinary means" since allegedly it would not have been possible (or at least would be 
highly improbable) for James to learn about the Natoma Bay or James Huston through ordinary means given the assumed lack of general availability of such information. It's not clear what claims Tucker has in view here (other than James allegedly naming the Natoma Bay and Jack Larsen), but clearly what Tucker is trying to do is dismiss ordinary sources as an explanation because that hypothesis would seem unable to account for everything. But no hypothesis can account for everything, and Tucker has nowhere shown, but only asserted, that reincarnation can explain such recalcitrant data. It's also hard to see how Tucker's argument works here without assuming the credibility of the Leiningers in ways that I've shown are implausible.

More importantly, though, neither Natoma Bay nor Jack Larsen, nor many of the other claims Tucker classifies as items of knowledge about James Huston count as early-bird claims (Tucker, 2016). So, Tucker has surely not ruled out ordinary explanations of the early-bird claims. It's understandable, of course, why someone unacquainted with the content of the ordinary sources James was exposed to might regard the early-bird claims as immune to such an explanation. But as I've shown, this is an illusion created by dark data and fact fudging.

\section{NATOMA BAY, JACK LARSEN, AND JAMES 3}

I have focused on the seven early-bird items Tucker lists (2016), but there are three other items Tucker discusses (2016). And in his chapter on James Leininger in Return to Life he regards them as additional earlybird claims. These are James allegedly giving his parents the names Natoma and Jack Larsen, and his signing his name James 3 on drawings of airplanes and battle scenes and his saying he was the third James.

We can easily dispense with "James 3." James started signing his name James 3 months after he turned three-years-old. That he continued signing his name James 3 after he turned four is hardly surprising given the attention this behavior had elicited. Moreover, James may very well have believed that he was the third James. After all, he had already internalized the reincarnation narrative his parents had suggested under the influence of Carol Bowman. Given these contextual factors, there's nothing psychologically peculiar here. There is nothing in need of an extraordinary explanation. 
So, this leaves us with Natoma and Jack Larsen.

On the face of it, these two claims, even if they do not have any obvious ordinary explanation, would not rescue the early-bird Leininger narrative from its impoverished evidential status. We often find ourselves in an epistemic situation where a set of facts seems to resist ordinary explanation. This is typically because of what we don't know, so-called dark data. But upon further scrutiny and as our knowledge expands, we acquire ordinary explanations. Our set of otherwise inexplicable facts accordingly shrinks. This pattern often continues as we acquire more information, and the domain of otherwise inexplicable facts shrinks even more. What does conscientiousness demand in such situations? It demands that we revise our degree of credence. As the set of otherwise explicable facts shrinks-say, from $100 \%$ to $80 \%$ to $60 \%$ to $40 \%$ to $20 \%$-we ought to be less confident that the remaining items will remain inexplicable. And we certainly ought not to appeal to the dwindling space of seemingly inexplicable facts as a lens through which we view the totality of facts to reassert their extraordinary nature.

This is precisely the situation in the Leininger case. Prior to the publication of this paper, neither the Leiningers nor Tucker acknowledged just how much of this case, especially the alleged earlybird claims and behavior of James, were easily and naturally explained by ordinary experiences and pedestrian sources of information. To date, the reincarnation interpretation of the presumed facts in this case has depended largely on an illusion of plausibility created by dark data, fact fudging, and dubious inferences. This needs to be emphasized at the outset to underscore a straightforward implication regarding the status of the two remaining early-bird items. One cannot plausibly leverage the seeming inexplicability of two facts to reinstate the reincarnation interpretation of the rest of the facts.

But we can otherwise dispense with these remaining features of the Leininger case.

In Section 5 I provided several reasons for skepticism about the Natoma attribution-skepticism with respect to whether James said Natoma, when he said it, and the narrative context in which he said it. We are simply not justified in accepting this claim given the level of obfuscation surrounding it. And we are certainly not justified in regarding this item as an early-bird claim. 
Tucker's justification for treating the Natoma attribution as an early-bird claim is implausible. He says, "we have definite documentation-from the Strange Mysteries interview and from printed records - of statements and behaviors from James Leininger, items that were recorded before James Huston was identified" (Tucker, 2013, p. 77). The printed records Tucker has in mind include the Natoma Bay Internet printout Bruce provided Tucker and which is timestamped 08/27/2000. As mentioned earlier in the paper, Tucker has reproduced this document for readers, with the website URL and date appearing in the footer (Tucker, 2016, p. 202, Fig. 1). ${ }^{67}$

But the timestamped document is not a record of anything James said before Huston was identified. It's simply the entry on the Natoma Bay from the online version of the Dictionary of American Naval Fighting Ships. Even if Bruce Leininger printed this document on the date in question, it's not definite documentation in the form of a printed record of a statement from James Leininger, which was recorded before James Huston was identified. In spring/summer 2002, the 2002 ABC program documented claims the Leiningers attributed to James at that time, months before the Leiningers had decided Huston was the previous personality. But the Natoma Bay document is no record of anything James said, much less a record of something he said prior to Huston being identified.

Tucker's justification for giving the Natoma attribution earlybird status is an inference from the Natoma Bay document (allegedly printed in 2000) and the testimony of the Leiningers in 2010 about what James allegedly said prior to Huston being identified, as well as the Leiningers' story about the circumstances that led to the printout. That's clearly a dubious strategy to underwrite an early-bird claim. Tucker says that, while other features of the James Leininger case are dependent on the Leiningers' memories, this particular piece of evidence isn't (Tucker, 2013, p. 69). That's false. Without the contextual narrative for the printout, it's useless as evidence for what James allegedly said before Huston was identified. But the contextual narrative depends on the reliability of the Leiningers' testimony. But their testimony is unreliable. And the opaque narrative surrounding the Natoma Bay document illustrates this. Since there are serious discrepancies in the historical record concerning when James uttered the word Natoma, the circumstances in which he said this, how the Natoma Bay printout 
came about, and whether James even said Natoma, the problem for Tucker is that this particular piece of evidence is married to egregious obfuscation and inconsistency. ${ }^{68}$ There is no justification for including it as an early-bird item.

The "Jack Larsen" attribution is no less problematic, though for different reasons.

According to the official 2009 chronology (SS, p. 89-90), the Leiningers elicited the following responses from James in a conversation surrounding one of his nightmares.

"Can you remember anyone else in the dream?" asked Andrea.

"Any friends?"

James concentrated for a moment; then his face lit up and he said, "Jack!"...

"Do you remember Jack's last name?" asked Andrea.

And then James said, very clearly, "Larsen. It was Jack Larsen." ...

"Was Jack James's friend?"

And James replied, "He was a pilot, too."

While it seems that James is here giving his parents some very specific information, the information is less specific than it first appears. Although we have a name, we don't know who the person is who is named, nor is there much of a narrative context to dial this in. We only know he is a pilot who seemed to have appeared in James's dreams and that James seems to say he is a friend. But it's not clear whether Larsen is supposed to be the previous personality or someone the previous personality knew. ${ }^{69}$ Even Bruce and Andrea Leininger couldn't agree on the identity of Larsen and his place in the narrative for nearly two years (SS, pp. 91-92, 95-96, 140-142; Tucker, 2013, p. 71). What James said was obviously not clear at the time, but this is problematic if we intend to justify claims about a match between James's Jack Larsen and a historical person by that name. $7^{\circ}$

It is true, of course, that there was a pilot named Jack Larsen on the Natoma Bay and he flew with Huston on the day Huston died. So, one can plausibly argue that there is a similarity between the facts and what James said. But are they identical? That's the real question. Similarity does not prove sameness. 
In the context in which James Leininger gave the name Jack Larsen, this is considerable vagueness, but vagueness and ambiguity are fertile grounds for cultivating a deceptive appearance of an identity between two different things, people, or events. This is because vagueness creates very broad parameters for the kind of facts that can subsequently be viewed as a match. We don't even know whether Jack is supposed to be a middle or first name, or a nickname-that is, assuming little James didn't make a mistake about the name altogether (cf. SS, p. 92). And even if we assume, as Tucker does, that James meant Jack Larsen was his friend (and not the previous personality), this doesn't sufficiently constrain the parameters for what would count as a match. Since the parameters of "friend" are not well-defined, especially since it's a twoyear-old using this word, the space of potential matches remains quite large. We're not told when they were friends, the circumstances of this, for how long, or anything specific about the friendship.

Here we see a logical sleight of hand that has arisen elsewhere in the Leininger case: the logical mistake of treating sufficiently similar events as if they're identical, what is referred to in probability theory as the law of near enough. ${ }^{12}$ Descriptions are often very similar to particular events or people without being genuine matches, and the vaguer or more ambiguous a description is, the more unrelated facts it will resemble in some way or other. But if we expand the space of potential matches in this way, it will be unsurprising that we find something that seems to be a match, however unrelated it might be. If Larsen is either the previous personality or another pilot who knew the previous personality, and either alive or dead, the parameters are considerably large. In that space the Jack Larsen of the Natoma Bay fits, as do many other Jack Larsens (and men with similar names) in WW2.

One can, of course, mask the dependence on the law of near enough by adding assumptions that tighten the parameters for a match. Assume that Jack Larsen is someone other than the previous personality but who knew the previous personality. Assume Larsen was a naval pilot, as Bruce Leininger does (SS, p. 96). Assume that James's Jack Larsen was present when the previous personality crashed his plane. Assume that the crash happened during the Battle of Iwo Jima (instead of at Iwo Jima). Assume Larsen is still alive. Assume there is consistency and significant continuity between James's nightmares 
over several months, and together with his waking state comments that he provided a coherent narrative of events set in WW2. Assume that when James said the name of the little man in his dreams was James, he was intending to give the name of the previous personality, rather than intending to refer to himself.

The problem is that these assumptions are mostly unwarranted, and some of them never even occurred to the Leiningers until after they learned about the Jack Larsen and James Huston of the Natoma Bay beginning in late 2000 and early 2001 . One can always combine the law of near enough and selection procedures to dial-in a potential match. The challenge is to avoid selection bias, which we don't if we use post hoc assumptions to constrain the space of possible matches. The raw claims attributed to James Leininger can with an equal show of plausibility be connected in many different ways. But Tucker has not provided any rules for doing this that dial-in the Jack Larsen of the Natoma Bay in a non-question-begging or otherwise logically suspect manner.

Tucker says, "It seems obvious in retrospect that James was saying he was a pilot named James who knew another pilot named Jack Larsen" (Tucker, 2013, p. 70). Perhaps, but this lends no warrant to the contention that James actually meant this. If the original claims are vague enough, any subsequent fact can be made to fit them. The resultant narrative will seem obvious in retrospect. It may also seem intuitive that we can reasonably tweak a narrative on the basis of facts we subsequently discover, but this can be a serious liability. We might incur the disadvantage of knowing only those facts we were unlucky enough to stumble upon first, facts that misled us into thinking a particular narrative was obvious when it was actually false. So, of course, given that we know Huston and Larsen were members of the VC-81 and served together on the Natoma Bay during the Battle of Iwo Jima, it looks obvious in retrospect that James was referring to himself as James Huston and the Jack Larsen in his dreams was a friend of Huston's. But had Bruce Leininger happened upon a different set of facts or adopted a different set of assumptions, a different conclusion about the identity of the previous personality would have seemed just as obvious in retrospect.

What I will call "counterfactual matches" are instructive here. 
If claims are vague enough, we can envision many counterfactual scenarios in which other facts would seem like an obvious fit to a different conjecture. Tucker thinks it's obvious that Larsen refers to a friend of the previous personality, but if Bruce Leininger had discovered a Corsair pilot named Jack Larsen who flew off a carrier in the Pacific and was shot down on the island of Iwo Jima, it would have been obvious in retrospect that Jack Larsen was the previous personality. Had this Jack Larsen test flown a Corsair in 1944, but later died after being shot down near Okinawa, it would have been obvious in retrospect that James was referring to himself as Jack Larsen.

Two other points are worth noting. While it may seem like the different elements involved in James's early-bird claims serve to delimit the range of possible matches, this is an illusion. It's quite the opposite. The law of combinations tells us that "the number of combinations of interacting elements increases exponentially with the number of elements." ${ }^{2}$ In the Leininger case, this is particularly egregious because not only is the identity of Jack Larsen ambiguous, so are the other elements being used to dial-in the identity of a previous personality. The Leininger narrative relies on the law of near enough with respect to several interacting elements of the story. What James says about Iwo Jima and the Corsair are, if not false, at least vague. And the reasoning above makes use of this combination of vague claims to significantly increase the number of scenarios that would count as a match.

Nor does inserting Natoma Bay into the equation make any significant difference to how the laws of probability work here. Even if that attribution were credible, there would still be an incredible amount of vagueness in the interacting elements of the case to permit hundreds of counterfactual matches. If Larsen had been a member of the U.S.S Sargent Bay and flew one of the TBM Avengers on the Chichi Jima run with Huston, then this would count as a match to James's claims. If Larsen had been a member of the VF-301 and test flew Corsairs with Huston off the U.S.S Gambier Bay, then this would have counted as a match. If Larsen had not served on the Natoma Bay but had otherwise participated in the Battle of Iwo Jima with Hustonperhaps they shared the sky on a particular mission or knocked back some skunked brewskies over a plate of two-day old meatloaf-that would count as a match. 
Now, if we grasp the conceptual point about counterfactual matches, we should see the salience of our ignorance for assessing actual matches with actual facts. What we don't know matters. What unknown actual facts are out there which, had the Leiningers discovered them first, would have made a different narrative look equally extraordinary? If we only focus on the facts that we have been unlucky enough to stumble upon first and which seem to fit a particular narrative (or are made to fit it), we are likely to ignore the salience of the possibility of other facts which, had we stumbled upon them instead, would have made a different narrative look equally extraordinary. ${ }^{73}$

So, while Jack Larsen and Natoma (and other features of the case) can be made to fit a narrative where James Huston is the previous personality, the method of generating this fit seems poorly insulated against the charge of ignoring how different laws of improbability combine to give the deceptive appearance of something extraordinary.

\section{CONCLUSION}

In this paper I have provided a detailed examination of the James Leininger case during its crucial formative phase, roughly spring 2000 to fall 2002. I've focused on features of the case Tucker classifies as early-bird items. These items, allegedly documented before the Leiningers identified Huston as the previous personality, are ostensibly the case's strongest features. Tucker claims reincarnation provides the best explanation of these items and that these items are evidence for reincarnation. I have argued that Tucker is incorrect.

As explained early in the paper, the evidential force of facts depends on two conditions.

(N) There are no additional facts that neutralize the evidential force of the presumed facts.

and

(D) There are no significant grounds for doubting the presumed facts.

If either (N) or (D) does not obtain, the prima facie evidential force 
of facts in support of a particular hypothesis or theory is defeated.

I have argued that neither (N) nor (D) is true with reference to the presumed early-bird items Tucker identifies in (2013) and (2016). Otherwise stated, Tucker has not presented a robust, credible chronology of events. We have many significant, additional facts Tucker has not acknowledged in his investigation and analysis. These facts neutralize the evidential force of the early-bird items-for example, by raising the probability and explanatory efficacy of non-reincarnation explanations. And the multi-faceted unreliability of the Leiningers gives us considerable reason to doubt the presumed facts of the case which Tucker adduces in favor of the reincarnation hypothesis.

What does this say about the merits of the James Leininger case as a whole?

Although I have focused on Tucker's early-bird items, my discussion has considered a wider range of alleged facts that encompass the twoyear formative phase of the case, as well as some items after fall 2002. I have at various points argued that my skeptical assessment of the earlybird items applies equally with respect to this wider range of presumed facts of the case. But the arguments l've presented would seem to raise significant doubt about the case as a whole. First, I've argued that significant doubt vitiates the foundational narrative of the case between 2000 and 2002. A weak foundation does not support a solid superstructure. Second, the early-bird items are the case's strongest features-if the stronger features don't survive critical scrutiny, a fortiori the weaker features won't. Finally, this paper raises significant doubt about particular features of the case-for example, the reliability of the Leiningers-that are essential to the larger story. So, the big-picture Leininger narrative is no less subject to doubt than the small-picture narrative. Neither warrants belief in the reincarnation hypothesis

\section{ACKNOWLEDGMENTS}

Between 2019 and 2021, I interviewed or corresponded with more than two dozen people as part of my investigation and research into the James Leininger case. I wish specifically to acknowledge the assistance of the following individuals: Stewart Bailey, Christy Bonds, Carol Bowman, Lucinda DeWitt, David Hand, John Fallis, Leslie Kean, Shalini 
Sharma, and Suzanne Stratford. Special thanks to the Cavanaugh Flight Museum for granting me permission to use the museum images in this paper. And special thanks to Cassidy Rees at the Cavanaugh for acquiring museum permissions on my behalf, as well as for providing information and photos of the museum. Much appreciation to Steve Baughman, Stephen Braude, and Keith Augustine for discussing this case with me during the course of my research and investigation. And Jim Tucker-although I have offered a critique of Tucker's investigation and analysis of this case, I'm grateful for the time he has taken since 2019 to discuss this case with me. Finally, Bruce Leininger-l had hoped he would've been willing to discuss his story with me beyond our initial email exchange and address the concerns developed in this paper. To date this has not happened. Nonetheless, I appreciate the answers he gave to my initial query.

\section{NOTES}

1 See B. Leininger, 2021. The Bigelow Institute for Consciousness Studies Awarded Leininger an Honorable Mention prize and \$20,000 for his essay in the 2021 competition for essays presenting the "best evidence" for life after death.

2 The quote is taken from Tucker's blurb in the front material of the Leiningers' 2009 book Soul Survivor (U.S. edition).

3 My research is based on variety of primary and secondary source documents (referenced in the paper), as well as correspondence and interviews I conducted with over two dozen people, including the individuals mentioned in the Acknowledgments at the end of this paper.

4 In this paper, I will provisionally accept the early-bird status of claims attributed to James in the 2002 ABC program. However, genuine early-bird claims must be documented prior to anyone attempting to verify the subject's claims or behavior (Stevenson, 1974, pp. 4, 71; Braude, 2003, p. 182). Once someone tries to verify a subject's claims, information acquired about a potential previous personality may influence what a subject subsequently says or influence the recollections of others and what claims they subsequently attribute to the subject. Bruce Leininger began attempting to verify James's claims as early as August 2000. From the very beginning, James's claims and 
his father's ongoing discoveries were inextricably entangled. Tucker says the 2002 program documents what James claimed before Huston was identified. This is a considerably looser standard since it allows an evolving narrative of past-life claims to be shaped by information acquired from attempts at verification, even if no decision has been made or conclusion reached about the identity of the previous personality.

5 Tucker cites psychiatrist Terr (1981) on childhood trauma to support his repetitive play conjecture. But this is problematic. First, post-traumatic play is symptomatic of trauma typically experienced in childhood. Second, Terr discusses 11 characteristics of post-traumatic play; Tucker narrowly focuses on a couple of these. Third, in Terr (2003) co-occurring symptoms are discussed as parts of a robust diagnosis of past trauma, but Tucker's suggested diagnosis doesn't consider any of this. Most importantly, both Terr and the DSM-V presuppose that the clinician has observed the subject engaged in play and has a robust account of the subject's developmental history and other salient biographical facts, including a traceable (hence known or knowable) incident in the subject's past that establishes a plausible cause for present observational behavior. Tucker is relying on behavior he never directly observed to infer that a child experienced a trauma as an adult in a past life. This seems like a misapplication of the clinical literature. One might just as plausibly conclude that James's behavior was either not post-traumatic play or he suffered a trauma in this life that did not show up on Tucker's radar. This disjunction of possibilities is considerably more probable than a conclusion arrived at by misapplying clinical work on childhood trauma.

${ }^{6}$ Assume hypothesis $h$ has some degree of probability $N$ given facts $f$. $\operatorname{Pr}(h \mid f)=N$. The evidential value of $f$ for $h$ is diminished just if there is some other fact(s) $f^{*}$, such that the conjunction of $f$ and $f^{*}$ results in $h$ having a probability less than the probability of $h$ given $f$ alone. The probability that lan was at Mr. Prescott's book launch party in Tuscan on Friday night may be high given that lan said he was planning to attend the party and three attendees claim to have seen lan there, but many additional facts would greatly lower this probability. Perhaps none of the surveillance video cameras at Mr. Prescott's house capture images of lan at the party, though they do capture images 
of the other attendees. Maybe surveillance cameras capture images of lan at a business conference in San Francisco on the evening of Mr. Prescott's party. Or perhaps we learn that lan's wife says lan was home all night and lan's twin brother, also a friend of Mr. Prescott, was in town for the weekend.

7 In correspondence (12/13/19) Leslie Kean sent me images of the front and back cover of Bruce Leininger's copy of the Blue Angels VHS tape. He had previously sent these images to Kean. Although I have the images of Bruce's copy of the video, Figure 1 is a photograph of my copy of the same $1994 \mathrm{VHS}$ tape with its original cover.

8 In correspondence (8/17/21), Tucker said he meant the video could not be the source of James's alleged specific knowledge about Huston's role in WW2. But the issue is not whether James acquired information about Huston's role in the war from the video, but whether the video is a plausible source for James's experiences, behavior, and claims in the first several months of the story long before he made any claim that was specifically or idiosyncratically true of Huston. It's not required that the video be the source of everything James said.

9 In correspondence (08/17/21), Tucker said that almost anything taken in isolation could be the source of James's nightmares. But the issue is not what, taken in isolation, could have influenced James's experience, but rather what provides a plausible explanation for it in the immediate context. To determine this, we should consider what James was actually exposed to and its causal relation to the content and affect in his dreams. A child who has nightmares about a fighter plane that is shot down is transparently less surprising if he's been repeatedly watching a video displaying such imagery than if he had not been exposed to such imagery.

${ }^{10}$ While the VHS tape is widely available, for ease of reference the cited timestamps are from a version of the video on YouTube.

"We might also ask whether a two-year old is likely to distinguish between an Iraqi MiG being shot down and a Blue Angels plane being shot down when these flash on the screen in proximity to each other in fast moving clips. We cannot easily dismiss the possibility that James perceived the imagery as showing a Blue Angels plane being shot down. Thanks to Steve Baughman for pointing this out to me. ${ }^{12}$ The Leiningers do acknowledge (SS, p. 57) that at one point in June 
2000 James's mother temporarily took the Blue Angels video away from James—she told him it broke-in the effort to divert his attention away from airplanes. But they give no indication of being aware of the specific content of the video or how it might plausibly have been affecting him.

${ }^{13}$ Tucker indicates that the Cavanaugh Flight Museum confirmed this when he checked with museum staff (2013, p. 69). As Tucker also indicates, the Corsair previously on display at the museum crashed at an airshow in Wisconsin on July 29, 1999. What Tucker does not say is that the pilot flying the Corsair when it crashed was Laird "Lad" Doctor, the director of the Cavanaugh Flight Museum. The crash left Doctor a quadriplegic. This detail is relevant to the Leininger story because the Corsair's fiery crash at the Oshkosh airshow continued to be publicly acknowledged and discussed at the museum as late as March 2000, shortly after James first visited. See AviationChannel.net (2017) and "10/22/99 Statement on Lad Doctor" (Cavanaugh Flight Museum 2000a).

${ }^{14} \mathrm{I}$ accessed the museum website using the Wayback Machine at Archive.com. See especially Cavanaugh Flight Museum (2000a, 2000b, 2000c).

${ }^{15}$ See Cavanaugh Flight Museum (200ob) for a listing of the museum's WW/2 artifacts in 2000 with links to images.

${ }^{16}$ See Cavanaugh Flight Museum (2000c) for a listing of the museum's WW2 fighter planes in 2000 with links to images.

${ }_{17}$ In correspondence (08/09/21), Christy Bonds (former Cavanaugh Gift Shop Manager) said, "we had several versions at different price points for Corsair toys and models." She also said the extensive collection of photos in the museum's gallery included images of Corsairs, as Figures 5 and 12 in the text illustrate.

${ }^{18}$ There is only one possible exception: James allegedly giving the word Natoma on August 27, 2000. But Tucker doesn't include this as an early-bird item in 2016. For reasons to be discussed in subsequent sections, the Natoma attribution is dubious.

19 If skepticism means withholding assent to reincarnation as the best explanation-that is, neither affirming nor denying that reincarnation is the best explanation-it will suffice to show that Tucker has not plausibly ruled out ordinary sources, in which case we don't have good 
enough reason to affirm that reincarnation is the best explanation. A stronger form of skepticism involves denying that reincarnation is the best explanation on the grounds that ordinary sources provide the better explanation.

${ }^{20} 1001$ crash.com.

${ }^{21}$ John Fallis, a long-time resident of Lafayette and friend of the late David Jeansonne, confirmed these facts in correspondence (9/3/2021) and during a phone interview with me (9/4/2021). The location of the Corsair in Lafayette until July 2000 and its subsequent arrival at the Cavanaugh in 2002 is documented at the Warbird Registry (2019). In correspondence (8/31/21, 9/1/21) Terry Sherman of Sherman Aircraft Sales confirmed the details of the purchase of Jeansonne's Corsair in April 2000 on behalf of Paul Morgan in the UK and the Corsair being flown from Lafayette Regional Airport to Jacksonville, Florida, in July 2000.

${ }^{22}$ Several sources indicate that there were flight simulators at the event. "In addition to our featured acts and static displays, the air show will also have a wide range of activities for all ages! There will be several aircraft simulators, antique cars, helicopter rides, photo opportunities in various aircraft and much more!" Sertoma Cajun Air Festival (2001a). The September 2001 Press Release for the event stated: "A tremendous military and civilian static display as well as several simulators will round out the exhibitions" (Sertoma Cajun Air Festival, 2001b). A post-event news article in the local paper stated: "Members of the audience were allowed to sit in a flight simulator complete with video footage showing the view from the cockpit. They also met pilots for pictures and autographs" (Bier, 2001).

${ }^{23}$ Phone interview with Fallis (9/4/2021). Fallis said he doesn't recall James ever saying anything about Huston or Wildcats or anything about memories of a past life. But James was known as the kid at school who drew pictures of airplanes and knew all about vintage planes.

24 The first in the series was F-16 Fighting Falcon (January 1993). Issue number 4 was $F_{4} F$ Wildcat (July 1995), number 7 was P-51D Mustang (January 1996), and number 8 was P-40 Warhawk (October 1996).

25 This is not only implicit in Tucker's discussion in (2013) and (2016), at times it's explicit-for example, when Tucker says the Leiningers 
knew of no (ordinary) way James could've learned a particular fact (Tucker, 2013, p. 83).

${ }^{26}$ Stratford (2012, 00:02:13-00:02:20). Stratford's interview was conducted in 2005.

${ }_{27}^{27}$ Unexplained Phenomena (2017, 00:12:17-00:12:27).

${ }^{28}$ A. Leininger (2009).

29 The first trip to the museum was mid-February 2000 and the nightmares began sometime between mid-April and May 1, 2000 (cf. B. Leininger, 2021, p. 8). So, the time gap between the first museum visit and his nightmares was between two and three months, not four as Andrea Leininger says. But Andrea Leininger's reasoning is otherwise odd given that she accepts that James's nightmares incorporate his waking state experiences as Huston from March 3, 1945. That's a temporal gap of 55 years, considerably longer than a few months. If a time gap of a few months prevents a past event from influencing one's dreams, an event 55 years in the past shouldn't be able to influence a dream. These kinds of logical inconsistencies vitiate the Leiningers' storytelling.

$3^{\circ}$ Hachette Book Group, 2009, 0:03:10-0:03:30.

${ }^{31}$ In correspondence (7/9/21) Bruce confirmed that this incident took place on Bruce's birthday in 2003, though he didn't acknowledge the Corsair video as the source of the statement he attributes to James. See below in text.

${ }^{32}$ Freeman, 2017, 0:31:22-0:31:29.

33 TVDB, 2021, So1, E22.

${ }^{34}$ The video also provides details about the Corsair with archival WW/2 footage. For example, this aviation video and others like it, discuss the difficulty of carrier landings-one of James's claims about Corsairs. Since Bruce Leininger is inconsistent about when James made certain claims, for all we know some of James's claims about Corsairs came after he saw this program, or perhaps from another video or television programs like it. There were many such programs on television during the late 1990 and early 2000 s.

35 Primary source documents composed during $\mathrm{WW}_{2}$ include U.S.S. Natoma Bay Airport Action Report (1945), U.S.S. Natoma Bay CVE62 War Diary (1945), as well as the U.S.S Sargent Bay CVE-83 Action Report (1945) and U.S.S Sargent Bay, March 1945 War Diary (1945). Bruce Leini- 
nger credits Natoma Bay Association historian John DeWitt with providing him with copies of primary source documents and many other materials (SS, pp. viii, 166. 175-76). The Leiningers also describe The Blue Book as a makeshift, unofficial log the Natoma Bay crew compiled in the 1980 s based on veteran recollections. The so-called Blue Book, also known as the LOGBOOK, is available at the U.S.S. Natoma Bay CVE-62 Historical Archive Website (2008-2014). Members of the Natoma Bay Association authorized the creation of the LOGBOOK in 1974. While it's true that the Blue Book contains veteran recollections of the war, much of its content is based on primary source documentation, as is illustrated in the content of portions of the LOGBOOK that cover the histories of the VC-81, VC-63, and VC-9 squadrons. See Wall and Sassano (n.d.).

${ }^{36}$ A. Leininger (2005).

${ }^{37} \mathrm{Jim}$ Tucker confirmed in correspondence (08/06/21) that he understood the Leininger narrative to include these additional claims about Huston surviving the crash impact and dying by drowning. He seems to have had Andrea Leininger's version in mind in his description of this early-bird item.

${ }^{8}$ U.S.S. Natoma Bay Aircraft Action Report, p. 4.

39 Thanks to Stewart Bailey for explaining this.

${ }^{40}$ In discussions with Stewart Bailey (correspondence 12/19/2019) about the details of Huston's crash, Bailey said that a 3 -inch incendiary round hitting Huston's plane could have caused a brief flash, even a large fire burst. But the plane need not have caught fire, much less remained on fire as it glided into the bay. Hence, it's possible that the Avenger pilots were correct about seeing a flash but simply misinterpreted this as Huston's plane being on fire. However, the other claims by Durham and Skelton, inasmuch as they imply serious damage to the plane, cannot be reconciled with the AAR's denial of this.

${ }^{41}$ Since the report provides details on the altitude of Huston's plane at time of nosing over ( 1,500 feet), his speed ( 175 knots), the angle of dive (45 degree), and the distance across Futami harbor (1.15 miles), we can calculate how long he had before the plane hit the water. Stewart Bailey calculated that Huston had as little as 5.08 seconds but certainly not more than 20 seconds. We don't know at what precise point in the run Huston was hit (except that it was apparently as he 
approached the harbor entrance), so this contributes to a generous 15 -second window. Futami Harbor is 1.15 miles across, which would take 20 seconds to cross at Huston's speed, so that permits fixing a generous upper limit to the time he had. What's most likely is that he had 5 to 10 seconds from the time his plane was hit to its crashing in the harbor. That's barely enough time to bail under optimal conditions, let alone trying to kick open a jammed canopy as the Leininger narrative purports. Huston would have had to (i) realize he'd been hit sufficiently bad enough to bail out, (ii) unbuckle, (iii) reach for the pair of canopy release rings and pull, (iv) realize the canopy didn't pop open, and ( $v$ ) attempt to push it open and/or reposition himself to kick it open, while the plane was in the 45 -degree gliding descent at 175 knots. Perhaps this is doable if he had as much as 10 seconds, but not if he had less time (Bailey correspondence 1/9/2020).

${ }^{42}$ Even this analysis is overly generous. Of the four confirmed claims, the first two make third probable. Also, if we take the alternative version of the claims attributed to James so that he said he flew a Corsair off the Natoma and died when his Corsair was shot down, the four confirmations reduce to two. So, of nine claims, the evidence only confirms two of them, disconfirms five of them, and two are neither confirmed nor disconfirmed. This is weak. Especially when we consider that of the two confirmed claims one is highly general and would likely be true even if the more specific claim about Jack Larsen was a chance hit.

${ }^{43}$ There are various questions we have to consider in assessing the reliability of the testimony of war veterans. I discussed these issues with Stewart Bailey (correspondence 12/12/2019). It's not simply the amount of time that has passed between the events and later recollections, but the original experiences may have involved skewed perceptions-for example, due to youth, inexperience, and being in lifethreatening circumstances. Bailey offered several examples of veterans who were sure they remembered incidents correctly, but which objective evidence subsequently demonstrated were incorrect. So, some degree of skepticism is warranted in accepting the testimony of the four Avenger pilots Bruce Leininger interviewed. That two of the Avenger veterans-Richardson and Skelton-were in poor health and the Leiningers' testimony is independently unreliable are further 
reasons to be skeptical of the alleged testimony of the Avenger pilots. Allegedly Jack Durham (from the U.S.S Sargent Bay) wrote down the details of March 3, 1945, in an informal memoir (SS, pp. 240-241). However, even if Bruce Leininger has accurately reported the details of Durham's memoir, it would contradict the AAR. Bruce also claims that the war diary for the U.S.S. Sargent Bay supports Durham's account since the diary claims that Huston's plane was hit in the engine and the front exploded in a ball of flames (SS, p. 242). However, neither the war diary nor the aircraft action report for the U.S.S. Sargent Bay says what Bruce Leininger attributes to it here.

${ }^{44}$ Although Tucker lists the early-bird claim as "Flew a Corsair," he indicates that "James seemed to be saying he was flying a Corsair when he crashed" (2016, p. 204). See also Judith Kroeger's article in the Daily Courier (Kroeger 2004), as well as Suzanne Stratford's 2005 news segment (Stratford, 2012, 0:01:36-0:02:20).

${ }^{45}$ James never explicitly said a lot of things which the Leiningers are nonetheless quite comfortable attributing to him when it supports their reincarnation narrative-for example, the full name of the carrier Natoma Bay, that their son claimed to be James Huston, Jr., that he died during the Battle of Iwo Jima, and that Jack Larsen was James Huston's friend.

${ }^{46}$ That James implied he crashed while flying a Corsair is even clearer in the 2003 Chronology to be discussed in subsequent sections. Under the time block of September-October 2000, we find the following "key items obtained from James's dreams: 1) Plane was on fire, crashed in the water, and the man was trapped. 2) Plane took off from a boat on the water. 3) Plane was shot down by Japanese. 4) When asked if he knew who it was he said 'James' we thought he was talking about himself having the nightmares. 5) When asked if he knew what type of air plane. He said it was a Corsair" (2003 Chronology, 1). James didn't say I flew a Corsair. He gave the name Corsair in response to his parents asking him what type of plane he was flying in the dream in which the Japanese shot him down and he died.

47 The book was Wright (1999, p. 3).

${ }^{48}$ Bruce provides this more contextually sensitive account in the 2004 Primetime program (Unexplained Phenomena, 2017, 0:08:26-0:08:50). 49 In Bowman (2010, p. 55) she says that, in their initial/early 2001 
correspondence, the Leiningers mentioned James's nightmares, his "uncanny knowledge about flying World War II airplanes," and his naming the Corsair.

$5^{\circ}$ One might suppose that the claims the Leiningers say James made in fall 2000 actually occurred at that time, but they simply didn't disclose any of these extraordinary claims to Bowman until spring 2002. In that case, the claims attributed to James wouldn't have been "new details" or the "latest revelations" from him (SS, p. xiv). And the Leiningers would've had ample opportunity to correct the misleading impression, both in their conversations with Bowman in 2002 and in reading Bowman's "Foreword" to their book. But the scenario envisioned here is otherwise implausible. In her early correspondence with Bowman, Andrea Leininger gave every indication of wanting to inform Bowman of James's display of extraordinary knowledge, which Andrea took to be evidence that her son was "experiencing a past life" (SS, p. 116). If James had made the extraordinary claims the Leiningers say he made in late Summer and Fall 2000, it's implausible that Andrea would not have shared any of these gems with Bowman and instead just offer as evidence that he was obsessed with World War II airplanes and could identify them.

${ }^{51}$ In her lectures, Bowman has said Andrea Leininger first contacted her in 2001. In personal correspondence (11/21/2021), Bowman told me that Andrea first contacted her in February 2001.

$5^{2}$ Honeywell, et al. (2020, 0:07:42-0:08:45). In correspondence (7/9/2021), I asked Bruce Leininger if I could see the original early correspondence between Andrea and Carol Bowman. He said he'd look for it but "it was 21 years ago." Taking him at his word implies the correspondence began in summer 2000. He has not responded to my follow-up queries. See Sudduth (2021).

53 Lucinda DeWitt claims her copy of the document is dated October 17, 2003, a month after the last events recorded in the chronology. Given that the Leiningers threw away their original notes, this may be the earliest extant written documentation of their story. In several emails I sent to Bruce Leininger between summer and early fall 2021, I asked him about any chronologies he might have composed in 2003 and whether any were sent to John DeWitt around this time. To date, Bruce has not responded, not even to deny that he is the au- 
thor of the document. See Sudduth (2021) to read my last two emails to Bruce Leininger.

54 "July-August 2000 Event: Issue of 'Past lives' surfaces. Andrea contacted Ms. Carol Bowman a specialist in past lives counseling. During this period Andrea spoke with her mother and her Mom who provided a resource she found on the internet a Ms. Carol Bowman. Carol had a practice on this phenomena. I was, at best, very skeptical. Andrea began a dialog with Carol. Based upon the guidance received Andrea began to talk to James about his nightmares in order to get him to stop the nightmares by using the techniques that Carol provided" (2003 Chronology, p. 1).

55 See B. Leininger (2021, p. 12). If Bowman first gave advice to the Leiningers in February 2001, James's past-life claim would've been more than six months after the Leiningers had been telling him that his experiences were of events that had happened to him before. $\mathrm{Cu}-$ riously, in Bruce Leininger's prize-winning BICS essay (B. Leininger, 2021), Bruce says nothing about Carol Bowman's involvement in the case. He has expunged her from the entire narrative.

${ }^{56}$ Tucker (2016) doesn't include this item in his list of early-bird claims because it wasn't included in the 2002 Strange Mysteries program, but he does discuss it and includes a reproduction of the printout with the URL and date-stamp in the footer. Tucker (2013) provides a defense of this item as an early-bird claim. I'll discuss Tucker's handling of the Natoma claim in Section 7.

572003 Chronology, p. 2.

${ }^{8}$ This certainly gives the impression that the document wasn't on anyone's radar during the three-month production of the 2002 ABC program. This is also supported by the testimony I received in a phone interview with a member of the production crew who said they didn't recall the Leiningers showing them the document in question during the interview process or at any point thereafter during production, though the crew member vaguely recalled "Natoma Bay" subsequently being part of the Leiningers' official story.

${ }^{99}$ A reporter who interviewed the Leiningers in 2005 told me that, during her interview, Andrea Leininger mimicked James's stuttering and stammering to illustrate the difficulty James had articulating the word the Leiningers decided sounded to them like Natoma. 
${ }^{60}$ I have added lowercase letters for items (1) and (3) since these are conjunctions of multiple claims, and it will be important to consider the claims individually as well as jointly.

${ }^{61}$ The testimony of the Avenger pilots about Huston's plane apparently being on fire doesn't sufficiently alleviate the difficulties here. First, it's possible to read their account as an interpretation of a brief burst of fire created by the shell impact to the plane, but not that the plane was on fire prior to hitting the water, as the Leiningers suggest. Second, if we cannot adjudicate the inconsistent testimonies, this aspect of the Leininger narrative would be neither confirmed nor disconfirmed. For reasons mentioned earlier, I favor the testimony of the primary source documents.

${ }^{62}$ Although in (2016) Tucker attributes to James the early-bird claim "died in the Battle of Iwo Jima," elsewhere he more accurately states the claim as "died at Iwo Jima" (2013, p. 78). The accompanying note he provides in (2016) indicates that Huston was killed during Iwo Jima operations on nearby Chichi Jima (2016, p. 204). This is his attempt to show that James's claim is somehow a partial match. But this is implausible. Iwo Jima and Chichi Jima are both islands in the Ogasawara archipelago in the Pacific Ocean, but this hardly makes them either the same location or even sufficiently similar to count as a match. If James had claimed to have died in a car crash in San Diego, California, and we later learned that the presumed previous personality died in a car crash in Santa Monica, California (about a hundred-and-fifty miles north of San Diego), James's claim would still be false, even though it would be true that Santa Monica is near San Diego and both are costal locations in California. Or suppose James had pointed to Gettysburg on a map of Pennsylvania and said that's where/when I was shot and died. Then we learned the presumed previous personality died of a gunshot wound at Mt. Pleasant, Pennsylvania (about 150 miles west of Gettysburg). James's claim would still be false, even if the death took place during the Battle of Gettysburg. It would also be false to say he died in the Battle of Gettysburg. If a falsehood can count as a (partial) match, it's unclear what couldn't count as a match.

${ }_{63}$ Assuming that Bruce Leininger's correction to the claim he attributes to James is accurate, he and Jim Tucker each ignore the quite plausible counterpoint that little James confused with and when, 
hardly a surprising kind of mistake for a two-year-old.

${ }^{64}$ Stewart Bailey confirmed this in correspondence and referenced two of the most well-known Corsair experts-Barrett Tillman and Nick Veronico-who make no claim about flat tires as something unique to the Corsair in their WW2 aviation books. Nor is it mentioned in standard Corsair manuals, though other problems are discussed. I confirmed this in correspondence with Barrett Tillman (9/11/2021).

${ }^{65} \mathrm{Dial}(1965$, p. 9).

${ }^{66} \mathrm{Ibid}$.

${ }^{67}$ The URL in the footer of the Natoma Bay printout is http://metalab.unc.edu/hyperwar/USN/ships/dats/CVE/cve62.html. This URL turns up a 404 error at ibiblio. A search in the Wayback Machine at https://web.archive.org shows that sometime, no later than fall 2000, the document originally hosted at metalab was moved to https:// www.ibiblio.org/hyperwar/USN/ships/dafs/CVE/cve62.html. Tucker checked the metalab URL in 2011 and discovered it wasn't active, but he found the same Hyperwar Natoma Bay document at ibiblio (correspondence $8 / 17 / 21$ ).

${ }^{68}$ In personal correspondence (8/30/21), Tucker told me that he does not recall how the copy of the Natoma Bay printout was made.

${ }_{69}$ It's worth noting that in the 2003 Chronology Bruce says James gave the name Jack Larsen and said he flew with him. That's not the same as what the 2009 account says.

$7^{0}$ Tucker (2013, p. 71) claims that Bruce Leininger's rejection of reincarnation influenced his early interpretation of Jack Larsen and led him to think James was dreaming about a pilot named Jack Larsen, not himself. This strikes me as a red herring. James's giving the name James as the name of "the little man" in the dream is naturally interpreted as James indicating that he-James Leininger-is the little man in the dream, and this is quite independent of whether one accepts or rejects reincarnation. Similarly, the ambiguity of the identity of Jack Larsen is baked into the claims James made. This also is independent of whether one accepts or rejects reincarnation.

${ }^{71}$ Hand (2014, p. 164).

${ }^{2}$ Hand (2014, p. 88).

73 Thanks to David Hand for discussing with me the application of the improbability principle to aspects of the Leininger case. 


\section{REFERENCES CITED}

1001crash.com. (2005-2021). 28 plane crashes in year 2000. https://www.1001crash. com/transport-page-plane_database-lg-2-numpage-200o.html

$A B C$ News. (2005). Parents think boy is reincarnated pilot. $A B C$ News archive. https://abcnews.go.com/Primetime/Technology/story?id=894217

Atkeison, C. (2020). U.S. Navy Blue Angels: Around the world (1993) [Video file] YouTube. https://www.youtube.com/watch?v=dJbgduKNvP8

AviationChannel.net. (2017). Vought $\mathrm{F}_{4} \mathrm{U}$ Corsair Crash on take-off [Video file]. https://www.youtube.com/watch?v=Fl7mb8-N $5 \mathrm{Gg}$

Bier, C. (2001, October 27). Blue Angels give kids special day. Daily Advertiser (Lafayette, LA). https://www.newspapers.com/image/539446513

Bowman, C. (2010). Children's past live memories and healing. Subtle Energies and Energy Medicine, 21(1), 39-58.

Braude, S. (2003). Immortal remains: The evidence for life after death. Rowman and Littlefield.

Cavanaugh Flight Museum. (1999). Museum guide. Neal Kimmel and Associates.

Cavanaugh Flight Museum. (2000a, March 2). https://web.archive.org/ web/20000302013224/http://www.cavanaughflightmuseum.com:80/index.html

Cavanaugh Flight Museum. (200ob, May 17). https://web.archive.org/ web/20000517073241/http://www.cavanaughflightmuseum.com/Artifacts. html

Cavanaugh Flight Museum. (2000c, September 29). https://web.archive.org/ web/20000929185201/http://cavanaughflightmuseum.com:80/Wwii2.html

Dial, J. F. (1965). The Chance Vaught F4U-I Corsair. Profile Publications.

Fischer, J. M., \& Mitchell-Yellin, B. (2016). Near-death experiences: Understanding visions of the afterlife. Oxford University Press.

Freeman, A. (2017, November 17). Battle stations: Corsair Pacific Warrior. [Video file]. https://www.youtube.com/watch?v=lersy6SGFAE

Hand, D. (2014). The improbability principle: Why coincidences, miracles, and rare events happen every day. Scientific American/Farrar, Straus and Giroux.

Hachette Book Group. (2009, June 26). Leininger family on Soul Survivor. [Video file]. https://www.youtube.com/watch?v=rNvJW6YJ3V8

Wall, B. (Ed.), \& Sassano, J. (Comp.). (n.d.). History of Composite Squadron Eighty One (VC 81). In U.S.S Natoma Bay logbook project.

https://natomabaycve62.org/logbook/pdfs/LogbookVC81.pdf

Honeywell, L., Leininger, B., \& Lovelace, T. (2020). The great beyond revealed [film]. A Honeywell Production.

ibiblio. (n.d.). USS Natoma Bay (CVE-62). In Dictionary of American naval fighting ships. Naval History Division, Office of the CNO, Navy Department. https:// www.ibiblio.org/hyperwar/USN/ships/dafs/CVE/cve62.html 
Kean, L. (2017). Surviving death: A journalist investigates evidence for an afterlife. Crown Archetype.

Kroeger, J. (2004, April 15). James Leininger, 6, of Lafayette, La. Loves airplanes. Daily Courier. http://www2.asa3.org/archive/asa/200711/0063.html

Leininger, A. (2005, July 9). Re: Leininger case on ABC-What did you think? Reincarnation Forum. http://reincarnationforum.com/threads/leiningercase-on-abc-what-did-you-think.646/page-2\#post-13696

Leininger, A. (2009, September 30). Re: Confessions of a skeptic. Soul Survivor blog. https://soulsurvivorbook.wordpress.com/2009/04/17/confessions-of-askeptic/\#comment-418

Leininger, B. (2009, June 20). Re: Confessions of a skeptic. Soul Survivor blog. https://soulsurvivorbook.wordpress.com/2009/04/17/confessions-of-askeptic/\#comment-98

Leininger, B. (2021). Consciousness survives physical death: Definitive proof of reincarnation. https://www.bigelowinstitute.org/contest_winners3.php

Leininger, B., \& Leininger, A. (2009). Soul survivor. Hay House UK.

Sertoma Cajun Air Festival. (2001a, December 18). https://web.archive.org/ web/20011218155434/http:/sertomaair.com:8o/entertainment.html

Sertoma Cajun Air Festival. (2001b, September 24). Swift Magic aerobatic team zooms into air show. [Press Release]. https://web.archive.org/web/20040805174343/ http://www.sertomaair.com/press_releases/9_24_ol.doc

Shermer, M. (2018). Heavens on earth: The scientific search for the afterlife, immortality, and utopia. Saint Martin's Press.

Stevenson, I. (1974). Twenty cases suggestive of reincarnation, 2nd ed. Rev. University Press of Virginia.

Stratford, S. (2012, November 19). Part 2: James Leininger's memories of another life. [Video file]. https://www.youtube.com/watch?v=TvD6Bq-ghqw

Sudduth, M. (2016). A philosophical critique of empirical arguments for postmortem survival. Palgrave Macmillan.

Sudduth, M. (2021, December 4). Correspondence with Bruce Leininger. Cup of Nirvana. http://michaelsudduth.com/correspondence-bruce-leininger/

Terr, L. C. (1981). Forbidden games: Post-traumatic play. Journal of American Academic Child Psychiatry, 20(4), 243-254.

Terr, L. C. (2003). Childhood traumas: An outline and overview. Focus: The Journal of Lifelong Learning in Psychiatry, 1(3), 322-333.

Tucker, J. (2013). Return to life: Extraordinary cases of children who remember past lives. Saint Martin's Press.

Tucker, J. (2016). The case of James Leininger: An American case of the reincarnation type. Explore, 12(3), 200-207.

TVDB (2021). Series / Battle Stations / Aired Order / All Seasons (September 25, 
2000-December 15, 2006). https://www.thetvdb.com/series/battle-stations/ allseasons/official

Unexplained Phenomena. (2017, September 24). Reincarnation-James Leininger (ABC Primetime) [Video file]. https://www.youtube.com/ watch? $\mathrm{v}=\mathrm{Cn} 9 \mathrm{nRdn} 5 \mathrm{FW} 4 \& \mathrm{t}=738 \mathrm{~s}$

U.S.S. Natoma Bay Aircraft Action Report (1945, March 3). VC-81 Reporting. Report \#80. OPNAV-16-V-\#S37, pp. 1-5.

U.S.S. Natoma Bay CVE62 war diary (1945, April 1). File No. CVE-62/A12/Aı6-3, pp. 4-6.

U.S.S. Natoma Bay CVE-62 Historical Archive website (2008-2014). https:// natomabaycve62.org

U.S.S. Sargent Bay CVE-83 Action Report: The occupation of Iwo Jima, 1o February to 11 March (1945). File No. CVE-83/A16-3. Serial: 020.

U.S.S. Sargent Bay, March 1945, war diary (1945). File No. CVE-83/A12-1. Serial: 031. Wall, B. (Ed.), \& Sassano, J. (Comp,). (n.d.). U.S.S. Natoma Bay logbook project. https://natomabaycve62.org/logbook/LBindex.html

Warbird Registry (2019). Corsair Registry / CORSAIR / Bu. 92399. http://www. warbirdregistry.org/corsairregistry/fg1-92399.html

Wright, D. (1999). The battle for Iwo Jima 1945. Sutton. 